\title{
Petrophysical constraints on the seismic properties of the Kaapvaal craton mantle root
}

\author{
V. Baptiste and A. Tommasi \\ Géosciences Montpellier, Université Montpellier 2 \& CNRS, CC 60, Place E. Bataillon, 34095 Montpellier cedex 5, France
}

Correspondence to: V. Baptiste (virginie.baptiste@gm.univ-montp2.fr)

Received: 1 July 2013 - Published in Solid Earth Discuss.: 1 July 2013

Revised: 25 November 2013 - Accepted: 7 December 2013 - Published: 29 January 2014

\begin{abstract}
We calculated the seismic properties of 47 mantle xenoliths from 9 kimberlitic pipes in the Kaapvaal craton based on their modal composition, the crystal-preferred orientations (CPO) of olivine, ortho- and clinopyroxene, and garnet, the Fe content of olivine, and the pressures and temperatures at which the rocks were equilibrated. These data allow constraining the variation of seismic anisotropy and velocities within the cratonic mantle. The fastest $P$ and $S_{2}$ wave propagation directions and the polarization of fast split shear waves $\left(S_{1}\right)$ are always subparallel to olivine [100] axes of maximum concentration, which marks the lineation (fossil flow direction). Seismic anisotropy is higher for high olivine contents and stronger CPO. Maximum $P$ wave azimuthal anisotropy $\left(\mathrm{AV}_{p}\right)$ ranges between 2.5 and $10.2 \%$ and the maximum $S$ wave polarization anisotropy $\left(\mathrm{AV}_{S}\right)$, between 2.7 and $8 \%$. Changes in olivine CPO symmetry result in minor variations in the seismic anisotropy patterns, mainly in the apparent isotropy directions for shear wave splitting. Seismic properties averaged over $20 \mathrm{~km}$-thick depth sections are, therefore, very homogeneous. Based on these data, we predict the anisotropy that would be measured by SKS, Rayleigh $\left(S_{\mathrm{V}}\right)$ and Love $\left(S_{\mathrm{H}}\right)$ waves for five endmember orientations of the foliation and lineation. Comparison to seismic anisotropy data from the Kaapvaal shows that the coherent fast directions, but low delay times imaged by SKS studies, and the low azimuthal anisotropy with with the horizontally polarized $S$ waves $\left(S_{\mathrm{H}}\right)$ faster than the vertically polarized $S$ wave $\left(S_{\mathrm{V}}\right)$ measured using surface waves are best explained by homogeneously dipping $\left(45^{\circ}\right)$ foliations and lineations in the cratonic mantle lithosphere. Laterally or vertically varying foliation and lineation orientations with a dominantly NW-SE trend might also explain the low measured anisotropies, but this model should also result in back-
\end{abstract}

azimuthal variability of the SKS splitting data, not reported in the seismological data. The strong compositional heterogeneity of the Kaapvaal peridotite xenoliths results in up to $3 \%$ variation in density and in up to $2.3 \%$ variation of $V_{p}, V_{s}$, and $V_{p} / V_{s}$ ratio. Fe depletion by melt extraction increases $V_{p}$ and $V_{s}$, but decreases the $V_{p} / V_{s}$ ratio and density. Orthopyroxene enrichment due to metasomatism decreases the density and $V_{p}$, strongly reducing the $V_{p} / V_{s}$ ratio. Garnet enrichment, which was also attributed to metasomatism, increases the density, and in a lesser extent $V_{p}$ and the $V_{p} / V_{s}$ ratio. Comparison of density and seismic velocity profiles calculated using the xenoliths' compositions and equilibration conditions to seismological data in the Kaapvaal highlights that (i) the thickness of the craton is underestimated in some seismic studies and reaches at least $180 \mathrm{~km}$, (ii) the deep sheared peridotites represent very local modifications caused and oversampled by kimberlites, and (iii) seismological models probably underestimate the compositional heterogeneity in the Kaapvaal mantle root, which occurs at a scale much smaller than the one that may be sampled seismologically.

\section{Introduction}

A wealth of seismological studies have investigated the structure of the Kaapvaal craton aiming at unraveling the thermal structure, the composition, and the deformation fabric of the cratonic root and at understanding the causes of its stability since Archean times, as inferred from Re-Os model ages obtained in kimberlite-born mantle xenoliths (Pearson et al., 1995). Tomographic models and receiver function data agree on the presence of a high velocity upper mantle lid 
on top of a low velocity layer (Jordan, 1978; Priestley, 1999; James et al., 2001; Li and Burke, 2006; Priestley et al., 2006). Most body and surface wave tomography models indicate that this lid is $200-250 \mathrm{~km}$ thick beneath the Kaapvaal craton (James et al., 2001; Chevrot and Zhao, 2007; Fishwick, 2010). A thinner high-velocity layer, extending to depths of 150 or $180 \mathrm{~km}$, was, however, imaged by other models (Sebai et al., 2006; Wang et al., 2008). Receiver function studies mapped sharp decreases in seismic velocities at 150 and $200 \mathrm{~km}$ depths (Wittlinger and Farra, 2007; Savage and Silver, 2008; Hansen et al., 2009; Adams and Nyblade, 2011).

Discriminating between these models, which point to different cratonic root thicknesses, and interpreting these geophysical data in terms of composition and temperature requires independent observations. The high seismic velocities beneath the Kaapvaal craton have indeed been alternatively attributed to thermal effects (Priestley and Tilmann, 2009) or to changes in composition (Begg et al., 2009). Similarly, the conversion at $150 \mathrm{~km}$ imaged by $S$ wave receiver functions was interpreted as produced by compositional layering, by anisotropy contrasts within the cratonic mantle (Wittlinger and Farra, 2007; Savage and Silver, 2008) or the lithosphereasthenosphere boundary beneath the craton (Hansen et al., 2009). Small-scale variations in seismic properties within the cratonic root also may not be imaged or interpreted unambiguously. Beneath the Bushveld complex, some, but not all body wave tomography models imaged velocities lower than the average ones in the craton, which have been attributed to either more fertile compositions associated with the $2 \mathrm{Ga}$ old Bushveld magmatism (James et al., 2001; Fouch et al., 2004a) or to a hotter present-day geotherm (Fouch et al., 2004a).

The deformation of the Kaapvaal craton has also been extensively investigated by seismic anisotropy studies (Silver et al., 2001; Fouch et al., 2004a; Fouch et al., 2004b; Silver et al., 2004; Adam and Lebedev, 2012; Vinnik et al., 1995, 2012). Silver et al. (2001) measured fast polarization directions that consistently followed the trend of geological structures and small SKS delay times (0.62 s on average), with almost null delays in the central Kaapvaal craton. They attributed this anisotropy to fossil deformation in the mantle lithosphere. Vinnik et al. (1995) attributed the same NNESSW fast polarization directions to asthenospheric deformation in response to African plate motion. Significant variations of SKS delay times were measured near Kimberley, which was interpreted as the boundary between a strongly and a weakly anisotropic domain (Fouch et al., 2004b). More recently, a Rayleigh wave azimuthal anisotropy model (Adam and Lebedev, 2012) proposed that the mantle fabric at lithospheric depths parallels the Archean-Paleoproterozoic crustal structures in the Limpopo belt and in the northern Kaapvaal, but is perpendicular to the crustal structures in the western part of the craton. Vinnik et al. (2012), using $P$ receiver functions and SKS waveform inversion, also observed belt-parallel, fast directions in the uppermost mantle near the
Limpopo belt. They also detected a change with depth in the orientation of the fast direction; the latter aligns progressively with current plate motion at depths $>160 \mathrm{~km}$. In summary, seismic anisotropy data derived from body and surface waves are mostly, but not always, consistent. Their interpretation is also not unique and may benefit from direct observations of the lithospheric mantle deformation and resulting anisotropy.

The Kaapvaal craton was affected by numerous kimberlite eruptions, mostly between the late Jurassic and the Cretaceous, but also during the Meso-Proterozoic and Paleozoic (Kramers and Smith, 1983; Allsopp et al., 1985; Phillips et al., 1998). These magmas carried xenoliths that provide direct sampling of the lithospheric mantle beneath the craton. The seismic properties of these peridotite xenoliths can be calculated from their crystal-preferred orientation (CPO) and composition data (Mainprice and Silver, 1993; Mainprice and Humbert, 1994). Such data constrain the possible seismic velocities and anisotropies within the Kaapvaal mantle root, as well as their dependence on the peridotites composition and crystal-preferred orientations. In the present study, we calculated the anisotropic seismic properties of 47 peridotite xenoliths from 9 kimberlite pipes, which sample different domains, depths, and ages of the Kaapvaal mantle root (Fig. 1). The present study represents a significant enrichment of the database of seismic properties of the Kaapvaal mantle root, as previous studies focused on either the composition- and depth-dependence of the isotropic seismic velocities (James et al., 2004) or the crystal-preferred orientation-induced anisotropy (Ben Ismail et al., 2001).

\section{The studied data set}

The 47 peridotite xenoliths used in this study come from 9 kimberlitic pipes (Kimberley, Jagersfontein, Monastery, Lentseng, De Beers, Finsch, Kamfersdam, Premier, and Mothae) from the Kaapvaal craton, with eruption ages of $1200 \mathrm{Ma}$ (Premier) and 120-87 Ma (all other pipes, see Baptiste et al., 2012, for details). These peridotites are mainly composed of olivine, orthopyroxene, clinopyroxene \pm garnet. When spinel is present, it is a minor phase. Thermobarometry data indicates that the studied peridotites were equilibrated at depths ranging between 83 and $187 \mathrm{~km}$ on a cold cratonic geotherm (Baptiste et al., 2012). The full description of the microstructures, crystal-preferred orientations (CPOs), and data on the water contents in olivine and pyroxenes in these xenoliths is presented in Baptiste et al. (2012), but their main characteristics are recalled below. The modal content, texture, olivine CPO type and intensity, and equilibration $P-\mathrm{T}$ conditions of all studied samples are summarized in Table 1.

The studied mantle xenoliths can be separated into two textural groups: the coarse-grained, which are composed by plurimillimetric to centimetric olivine and pyroxene crystals, and the sheared peridotites, which are characterized by 


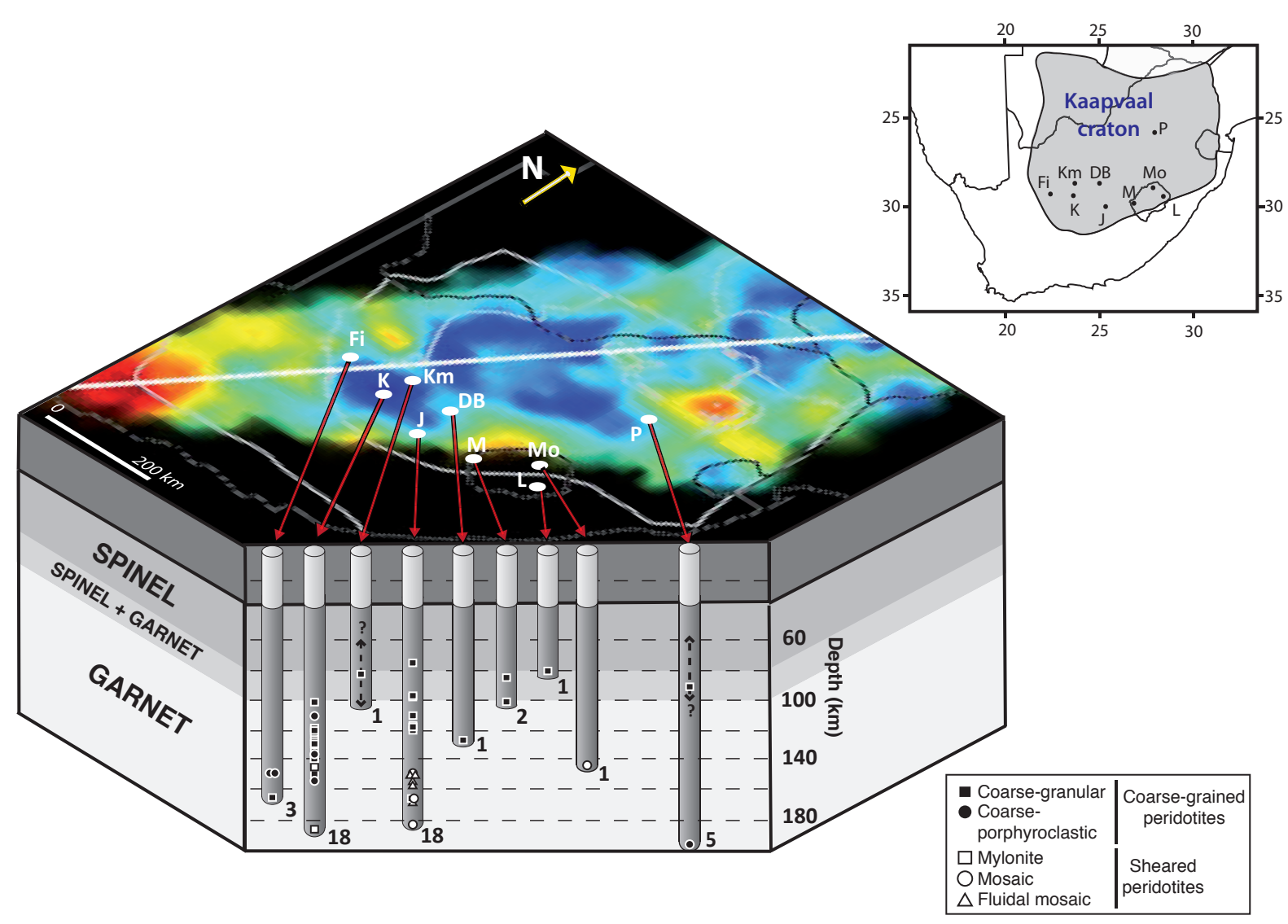

Fig. 1. Sketch displaying the location of the sampled kimberlitic pipes as well as the samples' depths and microstructures (after Baptiste et al., 2012) relatively to the $S$ wave tomography model of Fouch et al. (2004a) at $150 \mathrm{~km}$. Fi: Finsch, K: Kimberley, Km: Kamfersdam, J: Jagersfontein, DB: De Beers, M: Monastery, Mo: Mothae, L: Lentseng, P: Premier.

a matrix of fine-grained olivine (a few to $100 \mu \mathrm{m}$ ) and, occasionally, orthopyroxene that encloses millimeter-size garnet, pyroxene, and, sometimes, olivine porphyroclasts. The coarse-grained peridotites are the dominant textural group ( $72 \%$ of the studied samples), being observed at all depths and in all pipes (Fig. 1). They display most often strongly annealed textures, but coarse-porphyroclastic microstructures are also common. The sheared peridotites are only observed in the deeper part of the sampled columns (equilibration pressures $>4.5 \mathrm{GPa}$ ). Their textures range from mylonitic to fluidal or mosaic-like, probably due to variable post-deformational annealing. Based on their occurrence, microstructures and thermal evolution, Baptiste et al. (2012) interpreted the coarse-grained microstructures as the typical cratonic root microstructure, resulting from an early deformation episode followed by a long quiescence time, and the sheared peridotites as recording local modifications of the cratonic microstructure just before the xenolith extraction. Their formation is probably associated with the kimberlitic activity as proposed by Green and Guegen (1974).

Coarse-grained peridotites have in average more refractory compositions than the sheared peridotites (Table 1).
They are mainly harzburgites, with high orthopyroxene contents $(>20 \%)$. Sheared peridotites are mainly lherzolites, with highly variable garnet contents $(0-18 \%)$. In the studied samples, water contents in olivine and pyroxenes are very variable; maximum water contents in olivine increase up to $150 \mathrm{~km}$ depth, reaching up to 150 wt. ppm $\mathrm{H}_{2} \mathrm{O}$ (values obtained using the Bell et al. (2003) calibration; Baptiste et al., 2012). In contrast, olivines from samples equilibrated at depths $>150 \mathrm{~km}$ are almost dry.

\section{Methods}

Seismic properties of Kaapvaal xenoliths were calculated based on the olivine, orthopyroxene, clinopyroxene, and garnet CPOs, and on the modal compositions (Mainprice, 1990). The CPOs were measured by electron-backscattered diffraction (EBSD), producing crystal orientation maps, which covered the entire thin section (see Baptiste et al., 2012 for details on the EBSD data acquisition and treatment). Because olivine is the dominant phase in peridotites, largely determining their seismic properties, and because olivine compositions vary strongly among the studied samples (Table 1), 
Table 1. Olivine Mg\#, modal contents, equilibration conditions, calculated seismic properties and densities of the studied Kaapvaal peridotites.

\begin{tabular}{|c|c|c|c|c|c|c|c|c|c|c|c|c|c|c|c|c|}
\hline Locality & Sample & $\begin{array}{r}\mathrm{Ol} \mathrm{Mg \#} \\
(\%)\end{array}$ & \multicolumn{4}{|c|}{ Modal compositions (\%) } & $\begin{array}{r}\text { Temperature } \\
\left({ }^{\circ} \mathrm{C}\right)\end{array}$ & $\begin{array}{r}\text { Pressure } \\
(\mathrm{GPa})\end{array}$ & $\begin{array}{r}\text { Depth } \\
(\mathrm{km})\end{array}$ & $\begin{array}{r}\text { Density } \\
\left(\mathrm{g} \mathrm{cm}^{-3}\right)\end{array}$ & $\begin{array}{c}V_{p}^{(1)} \\
\left(\mathrm{km} \mathrm{s}^{-1}\right)\end{array}$ & $\begin{array}{r}\operatorname{Max} \operatorname{AV}_{p} \\
(\%)\end{array}$ & $\begin{array}{r}V_{s}^{(2)} \\
\left(\mathrm{km} \mathrm{s}^{-1}\right)\end{array}$ & $\begin{array}{r}{\operatorname{Max~} \mathrm{AV}_{s} \text { pol }}_{(\%)}\end{array}$ & $\begin{array}{r}\operatorname{Max} \mathrm{AVs}_{1} \\
(\%)\end{array}$ & $\begin{array}{r}\mathrm{Max} \mathrm{AVs}_{2} \\
(\%)\end{array}$ \\
\hline \multirow[t]{17}{*}{ KIMBERLEY } & KBBF6a & 90.8 & 74 & 13 & 4 & 9 & 926 & 3.8 & 121 & 3.3690 & 8.27 & 9.7 & 4.67 & 8.0 & 4.8 & 6.0 \\
\hline & KBBF6b & 91.0 & 82 & 8 & 4 & 6 & 908 & 3.7 & 118 & 3.3683 & 8.26 & 9.2 & 4.66 & 7.0 & 3.5 & 5.9 \\
\hline & KBBF8 & 94.3 & 81 & 19 & 0 & 0 & 1029 & - & 138 & 3.3500 & 8.19 & 10.0 & 4.64 & 7.4 & 6.1 & 2.6 \\
\hline & KBBF9 & 89.8 & 67 & 16 & 9 & 8 & 1102 & 4.7 & 149 & 3.3623 & 8.28 & 5.4 & 4.65 & 4.2 & 2.8 & 2.1 \\
\hline & KBBF10 & 92.4 & 72 & 27 & 1 & 0 & 948 & - & 125 & 3.3398 & 8.19 & 7.9 & 4.65 & 6.0 & 3.5 & 4.9 \\
\hline & KBBF11 & 93.6 & 88 & 11 & 1 & 0 & 1159 & 5.9 & 187 & 3.3618 & 8.17 & 4.7 & 4.55 & 3.3 & 4.6 & 2.9 \\
\hline & KBBF14 & 93.0 & 83 & 16 & 1 & 0 & 996 & - & 133 & 3.3518 & 8.20 & 5.4 & 4.64 & 5.4 & 3.6 & 2.8 \\
\hline & KBBF15 & 92.6 & 65 & 31 & 0 & 4 & 1067 & 4.3 & 137 & 3.3442 & 8.21 & 5.2 & 4.65 & 4.7 & 1.2 & 4.5 \\
\hline & KBBF16 & 93.3 & 71 & 26 & 0 & 3 & - & 4.0 & 127 & 3.3476 & 8.21 & 4.0 & 4.66 & 4.1 & 2.2 & 3.0 \\
\hline & KBBF18 & 92.2 & 75 & 17 & 6 & 0 & 850 & - & 110 & 3.3451 & 8.22 & 7.2 & 4.67 & 6.3 & 4.6 & 3.7 \\
\hline & KBBF20 & - & 65 & 35 & 0 & 0 & 800 & - & 102 & $* 3.3320$ & $* 8.17$ & $* 7.8$ & $* 4.67$ & $* 6.4$ & $* 3.2$ & $* 5.7$ \\
\hline & FRB1402 & 93.2 & 83 & 9 & 0 & 8 & 1023 & 4.6 & 146 & 3.3770 & 8.25 & 4.2 & 4.64 & 3.4 & 3.2 & 0.5 \\
\hline & FRB1404 & 93.5 & 59 & 36 & 1 & 4 & 987 & 4.4 & 140 & 3.3380 & 8.21 & 3.2 & 4.67 & 3.2 & 2.6 & 2.4 \\
\hline & FRB1422 & 93.5 & 65 & 31 & 0 & 4 & 994 & 4.4 & 140 & 3.3442 & 8.21 & 5.1 & 4.66 & 4.1 & 3.7 & 2.0 \\
\hline & FRB1423 & 91.8 & 68 & 18 & 4 & 10 & 851 & 3.8 & 121 & 3.3658 & 8.28 & 7.2 & 4.69 & 5.5 & 2.8 & 3.7 \\
\hline & FRB1447 & 93.4 & 73 & 23 & 1 & 3 & 968 & 4.2 & 133 & 3.3501 & 8.22 & 3.4 & 4.66 & 3.2 & 1.1 & 2.6 \\
\hline & FRB348 & 92.3 & 58 & 28 & 7 & 7 & 938 & 3.7 & 118 & 3.3478 & 8.27 & 5.6 & 4.70 & 4.3 & 2.4 & 2.9 \\
\hline \multirow[t]{16}{*}{ JAGERSFONTEIN } & KBJ6 & 90.7 & 84 & 9 & 3 & 4 & 1163 & 4.9 & 152 & 3.3673 & 8.22 & 6.0 & 4.61 & 4.8 & 3.7 & 1.8 \\
\hline & KBJ8 & 90.9 & 87 & 13 & 0 & 0 & 1219 & - & 168 & 3.3689 & 8.21 & 10.2 & 4.60 & 6.8 & 2.3 & 6.4 \\
\hline & KBJ14 & 91.3 & 70 & 5 & 12 & 13 & 1140 & 4.7 & 149 & 3.3822 & 8.36 & 5.7 & 4.69 & 4.1 & 2.0 & 3.3 \\
\hline & KBJ30 & 89.4 & 63 & 11 & 11 & 15 & 1282 & 5.8 & 184 & 3.3813 & 8.35 & 4.5 & 4.66 & 3.9 & 2.5 & 1.6 \\
\hline & KBJ33 & 89.3 & 68 & 8 & 6 & 18 & 1217 & 4.8 & 152 & 3.3925 & 8.35 & 7.6 & 4.68 & 5.3 & 1.9 & 4.5 \\
\hline & KBJ52 & 92.7 & 75 & 25 & 0 & 0 & 900 & - & 118 & 3.3425 & 8.18 & 7.3 & 4.64 & 5.7 & 4.1 & 3.5 \\
\hline & KBJ54 & 92.3 & 75 & 23 & 2 & 0 & 907 & 3.8 & 121 & 3.3431 & 8.19 & 8.2 & 4.65 & 7.5 & 5.9 & 4.4 \\
\hline & KBJ56 & 92.5 & 65 & 28 & 0 & 7 & 895 & 3.5 & 111 & 3.3524 & 8.24 & 6.3 & 4.69 & 5.4 & 5.1 & 2.3 \\
\hline & KBJ60 & 91.5 & 86 & 13 & 1 & 0 & 1190 & 5.2 & 165 & 3.3574 & 8.17 & 7.5 & 4.58 & 6.3 & 4.3 & 2.9 \\
\hline & KBJ62 & 92.6 & 64 & 36 & 0 & 0 & 759 & 3.1 & 98 & 3.3311 & 8.18 & 7.3 & 4.68 & 7.4 & 4.4 & 5.6 \\
\hline & KBJ63 & 91.3 & 82 & 10 & 3 & 5 & 1250 & 4.9 & 156 & 3.3689 & 8.23 & 7.5 & 4.61 & 7.7 & 3.9 & 4.4 \\
\hline & $\mathrm{J} 34$ & 92.0 & 59 & 29 & 5 & 7 & 656 & 2.4 & 76 & 3.3457 & 8.26 & 9.8 & 4.75 & 6.8 & 1.8 & 6.1 \\
\hline & $\mathrm{J} 41$ & 92.4 & 61 & 39 & 0 & 0 & 668 & 3.7 & 118 & 3.3283 & 8.17 & 4.0 & 4.66 & 4.9 & 4.5 & 2.0 \\
\hline & $\mathrm{J} 47$ & 90.7 & 85 & 6 & 8 & 1 & 1227 & 4.7 & 149 & 3.3615 & 8.22 & 7.1 & 4.61 & 5.7 & 4.6 & 1.6 \\
\hline & J57 & 92.4 & 79 & 18 & 3 & 0 & 765 & 3.1 & 98 & 3.3457 & 8.21 & 8.6 & 4.67 & 6.0 & 3.4 & 4.7 \\
\hline & J63 & 87.7 & 78 & 10 & 10 & 2 & 1176 & 5.2 & 165 & 3.3581 & 8.23 & 4.5 & 4.59 & 3.3 & 2.2 & 1.6 \\
\hline \multirow[t]{2}{*}{ MONASTERY } & ROM23 & 92.2 & 66 & 28 & 4 & 1 & 910 & 3.3 & 105 & 3.3373 & 8.21 & 5.0 & 4.69 & 4.9 & 3.1 & 3.0 \\
\hline & ROM69 & 92.2 & 76 & 20 & 3 & 1 & 784 & 2.6 & 83 & 3.3438 & 8.22 & 2.5 & 4.70 & 3.1 & 2.3 & 2.5 \\
\hline LENTSENG & PHN4274 & 93.1 & 62 & 33 & 2 & 3 & 1015 & 4.3 & 137 & 3.3387 & 8.21 & 3.5 & 4.66 & 3.5 & 3.0 & 2.5 \\
\hline MOTHAE & PHN1925 & 89.9 & 63 & 22 & 11 & 4 & 1306 & 4.6 & 137 & 3.3462 & 8.26 & 3.4 & 4.67 & 2.7 & 0.8 & 2.5 \\
\hline KAMFERSDAM & PHN5580 & 92.6 & 73 & 27 & 0 & 0 & - & - & - & $* * 3.2814$ & $* * 8.34$ & $* * 5.5$ & $* * 4.89$ & $* * 5.2$ & $* * 4.0$ & $* * 3.6$ \\
\hline DE BEERS & KBB2 & 93.3 & 66 & 33 & 0 & 1 & 917 & 4.0 & 127 & 3.3363 & 8.19 & 6.8 & 4.67 & 5.7 & 2.6 & 4.5 \\
\hline PREMIER & FRB1330 & 91.3 & 80 & 17 & 3 & 0 & 744 & - & 93 & 3.3455 & 8.21 & 9.4 & 4.68 & 6.7 & 2.3 & 6.1 \\
\hline & FRB1336 & 88.9 & 70 & 30 & 0 & 0 & - & - & - & $* * 3.3052$ & $* * 8.28$ & $* * 7.1$ & $* * 4.85$ & $* * 6.2$ & $* * 4.9$ & $* * 2.2$ \\
\hline & FRB1339 & 91.7 & 71 & 18 & 8 & 3 & - & - & - & $* * 3.3118$ & $* * 8.33$ & $* * 5.1$ & $* * 4.86$ & $* * 4.8$ & $* * 3.8$ & $* * 1.9$ \\
\hline & PHN5266 & 92.7 & 70 & 26 & 4 & 0 & - & - & - & $* * 3.3109$ & $* * 8.29$ & $* * 8.5$ & $* * 4.86$ & $* * 6.7$ & $* * 5.0$ & $* * 3.9$ \\
\hline & PHN5267 & 91.3 & 70 & 19 & 6 & 5 & 1464 & 6.5 & 171 & 3.3667 & 8.29 & 6.9 & 4.66 & 4.8 & 2.5 & 4.4 \\
\hline FINSCH & FRB1501 & 93.0 & 70 & 22 & 0 & 8 & 1030 & 4.6 & 149 & 3.3620 & 8.24 & 5.5 & 4.65 & 4.6 & 3.3 & 2.1 \\
\hline & FRB1512 & 92.0 & 68 & 22 & 0 & 10 & 1058 & 4.7 & 149 & 3.3657 & 8.26 & 5.0 & 4.66 & 4.1 & 3.3 & 1.9 \\
\hline & FRB1513 & 92.6 & 70 & 27 & 1 & 2 & 1037 & 5.2 & 165 & 3.3443 & 8.19 & 4.9 & 4.62 & 5.6 & 4.8 & 2.3 \\
\hline
\end{tabular}

Ol Mg\#, modal content and $P, T$ data from Baptiste et al. (2012).

(1) Mean $P$ wave velocity.

(2) Mean $S$ wave velocity.

$\mathrm{AV}_{p}: V_{p}$ azimuthal anisotropy; $\mathrm{AV}_{s}: V_{s}$ azimuthal anisotropy; $\mathrm{AV}_{1}$ : fast $V_{s}$ azimuthal anisotropy; $\mathrm{AV}_{2}$ : slow $V_{s}$ azimuthal anisotropy; maximum values.

* Seismic properties and density were calculated by only taking into account the sample equilibrium pressure and temperature, since olivine Mg\# was unknown.

** Seismic properties and density were calculated by only taking into account the mean olivine Mg\# of the sample, since the equilibrium conditions were unknown.

olivine elastic tensors were recalculated to account for the actual olivine mean forsterite content or $\mathrm{Mg} \#(\mathrm{Mg}+\mathrm{Fe} / \mathrm{Mg})$ in each sample. The elastic constants variation as a function of the olivine $\mathrm{Mg} \#$ was calculated by linear interpolation between the single-crystal elastic constant tensors measured in laboratory for fayalite, forsterite, and olivine with $\mathrm{Mg} \#$ of 90, 91, and 93 (Kumazawa and Anderson, 1969; Suzuki et al., 1983; Webb et al., 1989; Isaak et al., 1993; Abramson et al., 1997). For orthopyroxene, clinopyroxene, and garnet, the single crystal elastic tensors of Chai et al. (1997a), Collins and Brown (1998), and Chai et al. (1997b) at ambient pressure $(P)$ and temperature $(T)$ were used. Due to lack of experimental data, compositional changes could not considered for these phases. The density, the elastic constants and resulting seismic properties of each sample were calculated both at ambient pressure and temperature conditions and at its equilibration pressure and temperature. In both cases, the actual olivine $\mathrm{Mg \#}$ is considered. To account for the effect of pressure and temperature on the seismic properties, the elastic tensors and density of olivine, pyroxenes, and garnet were recalculated for depths between 40 and $200 \mathrm{~km}$ (a point at every $10 \mathrm{~km}$ depth) using the AnisPT8 software by $\mathrm{D}$. Mainprice, based on published pressure and temperature derivatives of the elastic constants for all major mineral 
phases (Abramson et al., 1997; Chai et al., 1997a, b; Collins and Brown, 1998) and the Kaapvaal geotherm of Baptiste et al. (2012). A Voigt-Reuss-Hill averaging was applied in all calculations. Equivalent "isotropic" seismic velocities were also estimated for each sample by averaging $P$ and $S$ wave velocities over all directions. Calculated seismic properties and elastic constants of all samples are summarized in Tables 1 and 2, respectively. The equilibration temperature and pressure of the samples were estimated using traditional geothermometers and geobarometers for mantle rocks, which have an uncertainty of up to $\pm 60^{\circ} \mathrm{C}$ and $\pm 0.2 \mathrm{GPa}$, respectively (see Baptiste et al. 2012 for more details). This uncertainty in the determination of the equilibration temperature and pressure results in an uncertainty in $V_{p}$ and $V_{s}$ of \pm 0.04 and $0.03 \mathrm{~km} \mathrm{~s}^{-1}$, respectively. In the present study, the seismic properties as a function of depth were not calculated using the elastic tensors of the different minerals calculated at the exact equilibration depth of the samples, but at every $10 \mathrm{~km}$ interval along the Kaapvaal geotherm of Baptiste et al. (2012). This simplification corresponds to a maximum pressure variation of $0.15 \mathrm{GPa}$, which is lower than the geobarometer uncertainty. It does not, by consequence, increase the uncertainty of the estimated seismic velocities. A probable additional source of uncertainty in the seismic velocities estimations at depth is the one related with the uncertainties in temperature and pressure derivatives of the elastic constants. However, the existing experimental data does not allow constraining this uncertainty. The three-dimensional distribution of seismic velocities and birefringence of $S$ waves relative to the samples' structural reference frame are displayed on lower hemisphere stereograms.

The mean seismic properties of six $20 \mathrm{~km}$-thick sections between 70 and $190 \mathrm{~km}$ depth were calculated by averaging the olivine composition and modal contents and adding up the crystal-preferred orientations of all samples equilibrated within the corresponding depth interval. This approach results in an upper bound for the estimated anisotropy, since the CPO summation is performed considering that the structural reference frames of all samples are parallel, that is, that the orientation of the foliation and lineation is the same for all samples within each depth interval.

To analyze the relations between the olivine CPO symmetry and intensity and the seismic anisotropy, the olivine CPO symmetry was characterized using the dimensionless BA index defined as

BAindex $=\frac{1}{2}\left(2-\left(\frac{\mathrm{P} 010}{\mathrm{G} 010+\mathrm{P} 010}\right)-\left(\frac{\mathrm{G} 100}{\mathrm{G} 100+\mathrm{P} 100}\right)\right)$,

where $\mathrm{P}$ and $\mathrm{G}$ are indexes used to characterize the shape of the distribution ( $\mathrm{P}$ for Point and $\mathrm{G}$ for Girdle) of the olivine principal axes ([100], [010] and [001]); these indexes were calculated from the eigenvalues of the normalized orientation matrix as $P=\lambda 1-\lambda 3$ and $G=2(\lambda 2-\lambda 3)$, calculated using the MTEX texture analysis toolbox (Hielscher and Schaeben, 2008; Mainprice et al., 2011). This index allows the classifi- cation of the olivine $\mathrm{CPO}$ into 3 types: axial [010] $(\mathrm{BA}<0.4)$, orthorhombic $(0.4<\mathrm{BA}<0.6)$, and axial $[100](\mathrm{BA}>0.6)$.

The olivine CPO intensity is characterized by the dimensionless $J$ index, which is the volume-averaged integral of the squared orientation densities defined as

$J=\mathrm{f}(\mathrm{g})^{2} \mathrm{~d} g$,

where $f(g)$ is the orientation distribution function (ODF) and $\mathrm{d} g=\mathrm{d} \varphi_{1} \mathrm{~d} \varphi \mathrm{d} \varphi_{2} \sin \varphi \pi^{2} \cdot \varphi_{1}, \varphi$, and $\varphi_{2}$ are the Euler angles that define the rotations allowing for coincidence between the crystallographic and external reference frames. In natural peridotites, olivine CPO $J$ indexes vary between 2 and 20, with a peak at 8-10 (Ben Ismaïl and Mainprice, 1998; Tommasi et al., 2000). $J$ indexes were calculated based on the mean orientation of each grain, using the SuperJctf program by D. Mainprice (ftp://www.gm.univ-montp2.fr/ mainprice//CareWare_Unicef_Programs/) with a $10^{\circ}$ Gaussian half-width, $1^{\circ}$ cells, and truncation of the ODF at $22^{\circ}$.

\section{Results}

\subsection{Seismic anisotropy}

Seismic anisotropy patterns for samples representative of the different microstructures and olivine CPO symmetry patterns observed among Kaapvaal xenoliths (Table 1 and Baptiste et al., 2012) are illustrated in Fig. 2. At first order, seismic anisotropy patterns for all samples have similar characteristics, independently of the peridotite microstructure and olivine CPO symmetry. The fastest and slowest $P$ wave and slow $S$ wave $\left(S_{2}\right)$ propagation directions are aligned with the olivine [100] and [010] axes maxima, respectively. The orientation of the [100] maximum also controls the direction of polarization of the fast $S$ wave $\left(S_{1}\right)$. Moreover, when the lineation (crystals elongation marking the structural $X$ direction) and foliation (crystals flattening marking the plane normal to the $Z$ structural direction) could be identified, the [100] maximum corresponds to the lineation, which marks the fossil flow direction. The fast split shear wave $\left(S_{1}\right)$ is thus polarized in the plane containing the wave propagation direction and the fossil flow direction in the mantle lithosphere. The highest $V_{p} / V_{S_{1}}$ ratio is also parallel to this direction and the lowest $V_{p} / V S_{1}$ ratio is observed for waves propagating normal to it.

Changes in olivine CPO symmetry result in second order variations in the seismic anisotropy pattern. Peridotites displaying an axial [100] CPO tend to show slow $P$ wave velocities for all directions normal to the lineation, instead of a clear $V_{p}$ minimum at high angle to the foliation. $S$ wave polarization anisotropy patterns are also sensitive to the CPO symmetry. Samples with an axial [100] olivine CPO display high $V_{s}$ anisotropy $\left(\mathrm{AV}_{s}\right)$ for directions of propagation in the foliation plane, but at high angle to the lineation ( $Y$ structural direction) and a minimum anisotropy for propagation along 

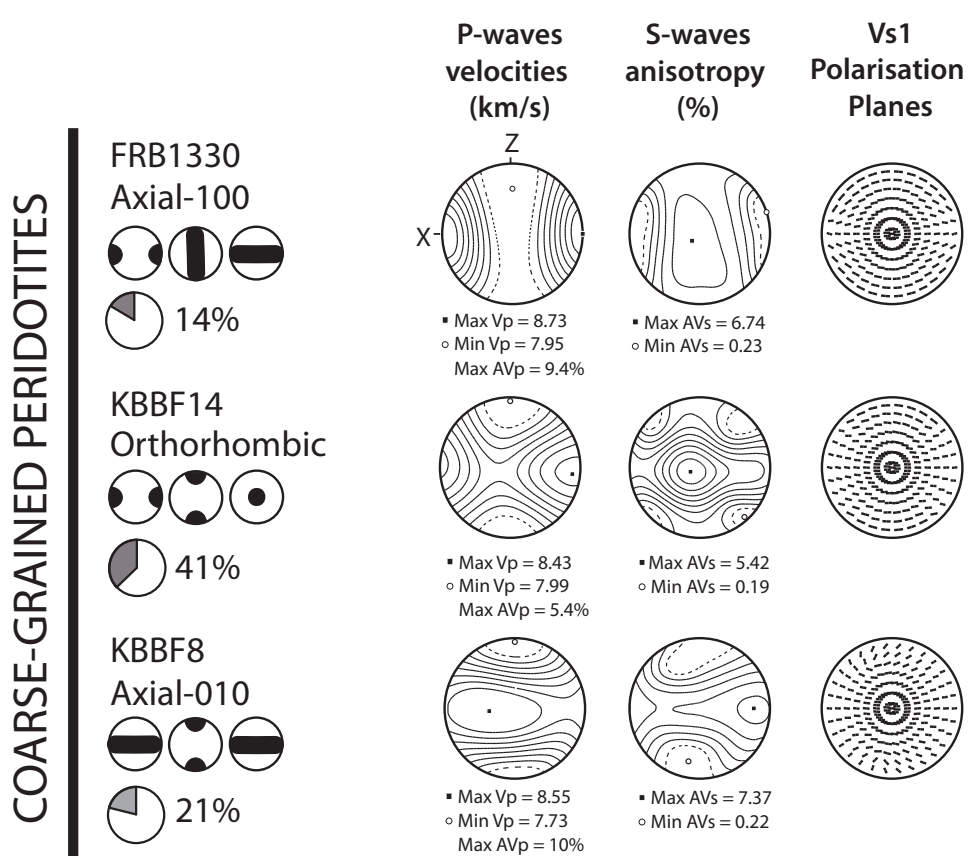
S1-waves
velocities
$(\mathrm{km} / \mathrm{s})$
S2-waves
velocities
$(\mathrm{km} / \mathrm{s})$
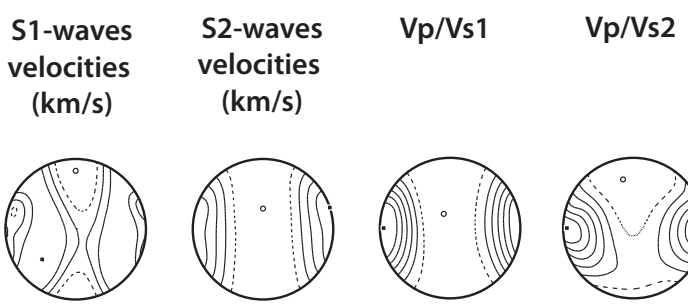

- $\operatorname{Max} V s 1=4.83$

Min Vs1 $=4.72$

$-\operatorname{Max} V p=8.73$
$-\operatorname{Min} V p=7.95$

$\operatorname{Max} \operatorname{AVp}=9.4 \%$

- Max AVs $=6.74$
- Min AVs $=0.23$
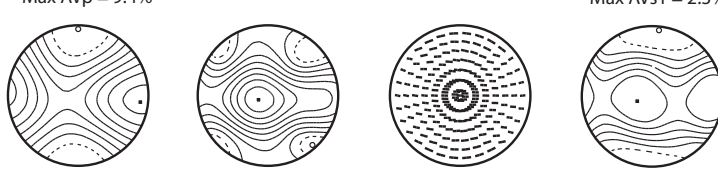

- $\operatorname{Max} V \mathbf{2} 2=4.75$

$\operatorname{Min} V_{s 2}=4.47$

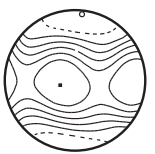

- $\operatorname{Max} V p=8.43$

$\circ \mathrm{Min} V \mathrm{p}=7.99$

- Max AVs $=5.42$
- Min AVs $=0.19$
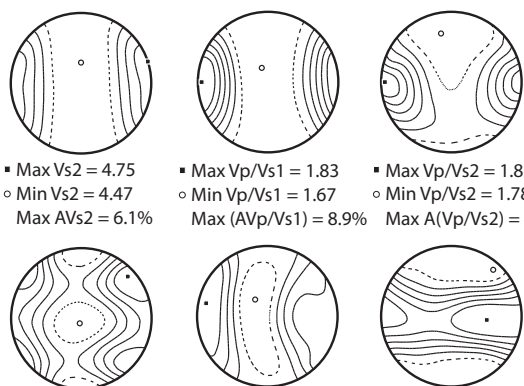

- $M a x V p / V s 1=1.83 \quad$ - Max Vp/Vs2 $=1.85$ Min Vp/Vs1 $=1.67 \quad \circ$ Min Vp/Vs2 $=1.78$ $\operatorname{Max} \mathrm{AVp}=5.4 \%$
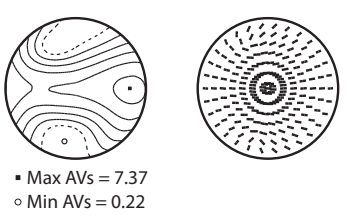

- $\operatorname{Max} V s 1=4.77$

Min Vs1 $=4.61$

$\operatorname{Max}$ AVs $1=3.6 \%$

- $\operatorname{Max} V s 2=4.64$

Min Vs2 $=4.52$

$\operatorname{Max}\left(\operatorname{AVp} / \mathrm{Ns}_{1}\right)=8.9 \% \quad \operatorname{Max} \mathrm{A}(\mathrm{Vp} / \mathrm{Ns} 2)=4.1 \%$
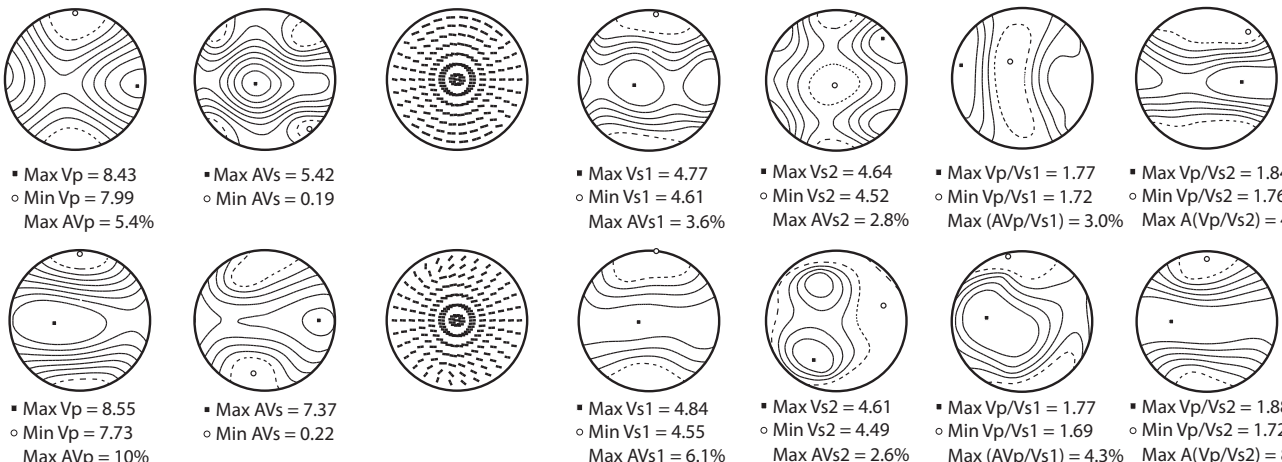

- Max Vp/Vs1 = 1.77 - Max Vp/Vs2 $=1.84$ Min $V p / V s 1=1.72 \quad \circ M i n V p / V s 2=1.76$
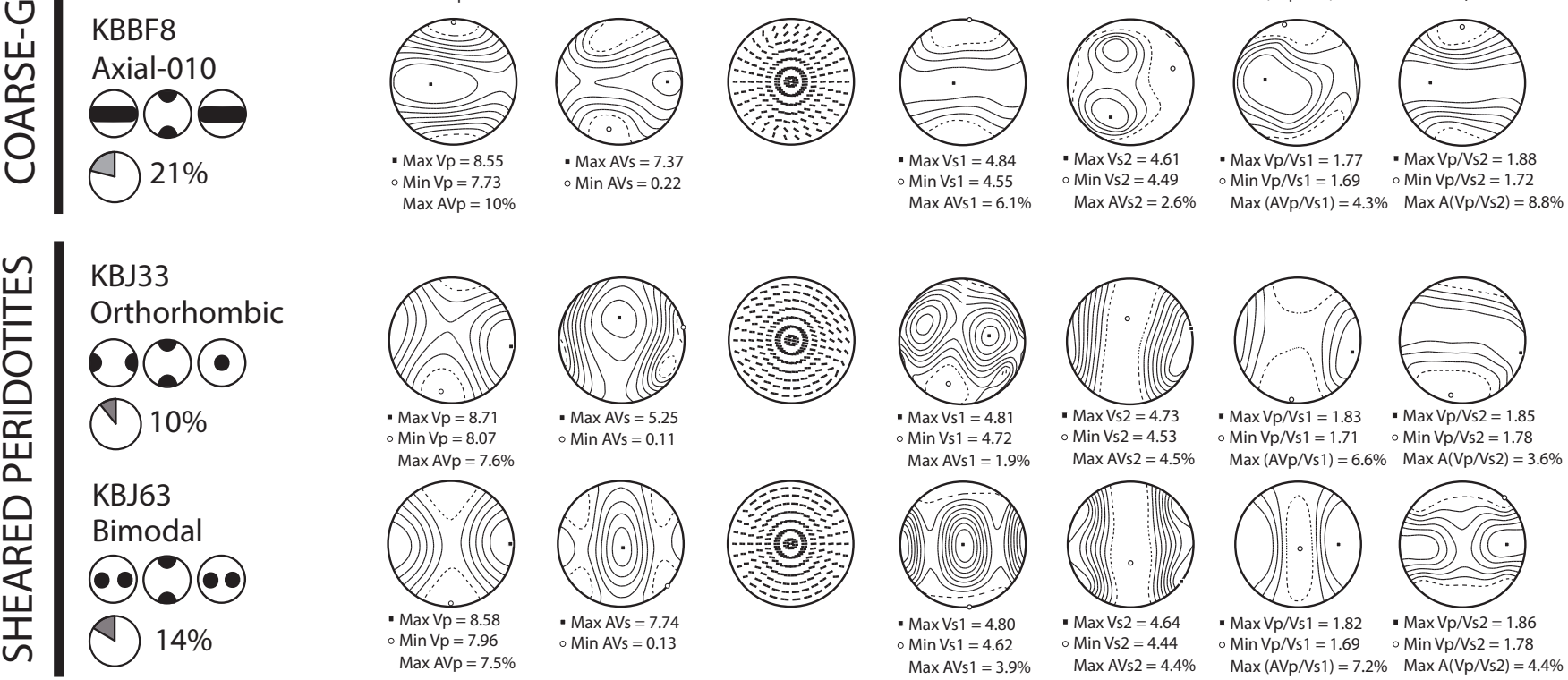

Fig. 2. Calculated seismic properties of the Kaapvaal coarse-grained and sheared peridotites showing different olivine CPO patterns. From left to right, are displayed the 3-D distributions of $P$ wave velocities $\left(V_{p}\right), S$ wave polarization anisotropy $\left(V_{S}\right)$, the orientation of fast shear wave polarization plane, $S_{1}$ wave velocities $\left(V_{S_{1}}\right), S_{2}$ wave velocities $\left(V_{S_{2}}\right), V_{p} / V_{S_{1}}$, and $V_{p} / V_{S_{2}}$. Black squares and white spots indicate maximum and minimum values, respectively.

the lineation ( $X$ direction) and more rarely at $45^{\circ}$ to the lineation in the $X Z$ plane. The slowest $S_{1}$ wave propagation is always located at high angle to the foliation (parallel to the $Z$ structural direction), while the fastest propagation is in the foliation plane, at $45^{\circ}$ to the lineation. $S_{2}$ wave velocity is maximum close to the lineation or in the $X Z$ plane, at $\sim 10^{\circ}$ to the lineation. The $V_{p} / V_{S_{1}}$ ratio is highest parallel to the lineation ( $X$ structural direction) and lowest at high angle to the foliation ( $Z$ structural direction).

In contrast, peridotites with an axial [010] CPO show high $S$ wave polarization anisotropy for propagations along the foliation plane and low anisotropy for $S$ waves traveling at high angle to the foliation. The strongest $S$ wave birefringence is usually observed for waves propagating at low angle to the lineation, but it may also be oblique to it. $S_{1}$ wave velocity is higher in the foliation plane. The fastest $S_{1}$ waves may be aligned with either the $X$ or the $Y$ structural directions or even at $45^{\circ}$ to these directions. This variability in the orientation of the maximum $S$ wave birefringence and of the fastest $S_{1}$ waves depends on the actual symmetry of the olivine CPO; samples with lower BA indexes have both maxima at low angle to the $X$ structural direction. $S_{2}$ wave velocity is minimum along the $X Z$ plane. The $V_{p} / V_{S_{1}}$ ratio tends to show high values in the foliation plane and low values at high angle to it ( $Z$ structural direction).

Peridotites with an orthorhombic CPO show patterns intermediate between the two described previously. The maximum $S$ wave polarization anisotropy is at low angle to the $Y$ structural direction, similarly to that observed for samples with an axial [100] CPO, but, the minimum $S$ wave 
anisotropy is in the $X Z$ plane, at $45^{\circ}$ to both the lineation ( $X$ structural direction) and to the foliation $(Z$ structural direction). The $S_{1}$ wave velocity is most often the highest along the foliation plane, parallel to both $X$ and $Y$ structural directions, or at $45^{\circ}$ to these axes. The slowest $S_{1}$ wave propagation is at high angle to the foliation ( $Z$ structural direction). The $S_{2}$ wave velocity is maximum parallel to the lineation or at $45^{\circ}$ to the lineation in the $X Z$ plane, as in the example displayed in Fig. 2. It is minimum along the $Y Z$ plane. The maximum $V_{p} / V_{S_{1}}$ ratio is observed along the foliation plane and the minimum $V_{p} / V_{S_{1}}$ ratio is located close to the $Z$ structural direction.

Peridotites with bimodal olivine $\mathrm{CPO}$ have also intermediate patterns, with maximum $S$ wave polarization anisotropy for propagation directions close to the $Y$ structural direction. The minimum $S$ wave polarization anisotropy is observed for propagation directions at $45^{\circ}$ to the lineation in the $X Z$ plane. In a few cases, however, the $S$ wave polarization anisotropy is minimum at high angle to the foliation. $S_{1}$ wave velocity is the highest in the foliation plane, close to both $X$ and $Y$ structural directions and it is the lowest at high angle to the foliation ( $Z$ structural direction). The $S_{2}$ wave velocity is the highest along the $Y Z$ plane. The $V_{p} / V_{S_{1}}$ ratio is maximum along the foliation and minimum at high angle to the foliation ( $Z$ structural direction).

Despite the weak variation in the patterns, xenoliths from the Kaapvaal craton show a wide range of seismic anisotropy intensities (Fig. 3, Table 1). Maximum anisotropy values range between 2.5 and $10.2 \%$ for $P$ wave azimuthal anisotropy $\left(\mathrm{AV}_{p}\right)$, between 2.7 and $8 \%$ for $S$ wave polarization anisotropy $\left(\mathrm{AV}_{s}\right)$, between 0.8 and $6.1 \%$ for $S_{1}$ wave propagation anisotropy $\left(\mathrm{AV} S_{1}\right)$, and between 0.5 and $6.4 \%$ for $S_{2}$ wave propagation anisotropy $\left(\mathrm{AV}_{S 2}\right)$. All anisotropies show a positive covariance with the olivine $\mathrm{CPO}$ strength (Fig. 3a, b); samples with stronger olivine CPOs are more anisotropic. Yet, this variation is not linear, as observed in previous studies (Ben Ismaïl and Mainprice, 1998): anisotropy increases fast with increasing CPO strength up for low $J$ indexes $(\leq 4)$, but slow afterwards, tending to stabilize for $J$ indexes $>8$. Coarse-grained peridotites show more variable olivine CPO intensities ( $J$ indexes range between 2-11). However, their maximum seismic anisotropies are in the same range as those displayed by the sheared peridotites (Fig. 3a, b). These variations suggest that the modal composition has also an important effect on the seismic anisotropy of these samples.

The presence of pyroxenes and garnet is known to dilute the bulk anisotropy of the rock (Mainprice and Silver, 1993; Mainprice et al., 2000). Samples with high modal olivine, and therefore lower pyroxene and/or garnet contents, tend to have higher maximum $\mathrm{AV}_{p}, \mathrm{AV}_{1}$ and $\mathrm{AV}_{S 2}$. However, the dependence is weaker than the one on the olivine CPO strength (compare Fig. 3c and a). The dependence on the olivine content is even less marked for the $S$ wave polarization anisotropy (Fig. 3d).
There is no simple relation between the olivine CPO symmetry, characterized by the BA index, and the maximum $P$, $S, S_{1}$, and $S_{2}$ wave anisotropies (Fig. 3e, f). Samples with an olivine axial [100] CPO tend to show higher maximum $P$ and $S_{2}$ propagation anisotropies than those with an orthorhombic CPO, which are themselves more anisotropic than those with an axial [010] CPO. The relation is less clear, however, for $S$ wave polarization and $S_{1}$ propagation anisotropies. Moreover, this relation probably reflects more a variation in the olivine CPO intensity then a strong dependence on the olivine CPO symmetry. In the studied data set, samples with axial [100] tend to have stronger olivine CPO, but this behavior is not a general one in naturally deformed peridotites, which may also display very strong axial [010] olivine CPO patterns (e.g., Tommasi et al., 2008).

\subsection{Effect of compositional variations on the density and isotropic seismic velocities}

Kaapvaal mantle xenoliths record a long and complex history. Early partial melting and extraction of high melt fractions are evidenced by the refractory compositions (olivine Mg\#>92), which are common among the coarse-grained peridotites (Table 1). However, the large variability in modal and chemical compositions of these xenoliths implies that the craton mantle root has been subsequently modified by multiple metasomatic events. The high orthopyroxene content observed in many coarse-grained peridotites has been attributed to percolation of Si-rich fluids and/or melts (e.g., Bell et al., 2005; Wasch et al., 2009; Baptiste et al., 2012). In many xenoliths, secondary crystallization of phlogopite, clinopyroxene and garnet point to reactions with percolating K-rich melts at high pressure (e.g., Grégoire et al., 2003; Griffin et al., 2003; Bell et al., 2005; Baptiste et al., 2012). These metasomatic events may have also allowed for rehydration of the Kaapvaal mantle root above $150 \mathrm{~km}$ depth (Baptiste et al., 2012). Finally, local high-stress deformation, which was probably shortly predated by a late metasomatic event by Krich fluids and/or melts (Wasch et al., 2009), produced the sheared peridotites (Baptiste et al., 2012).

This compositional variability resulted in significant variations in both density and seismic velocities as illustrated in Fig. 4, where densities and isotropic $P$ and $S$ wave velocities at ambient conditions are displayed as a function of the olivine $\mathrm{Mg \#}$, the orthopyroxene, and the garnet content of each sample. The density of Kaapvaal samples varies by up to $3 \%$ (Fig. $4 \mathrm{a}$ e, i). It decreases with increasing olivine Mg\# and orthopyroxene content, but strongly increases with increasing garnet content. The linear correlation with the garnet content is particularly striking. This later effect is dominant in the sheared peridotites, where the garnet content may attain up to $18 \%$.

$P$ wave velocities vary by up to $2.2 \%$ with the peridotites composition (Fig. $4 \mathrm{~b}, \mathrm{f}, \mathrm{j}$ ). There is a weak positive covariance between $P$ wave velocities and garnet content. $P$ wave 


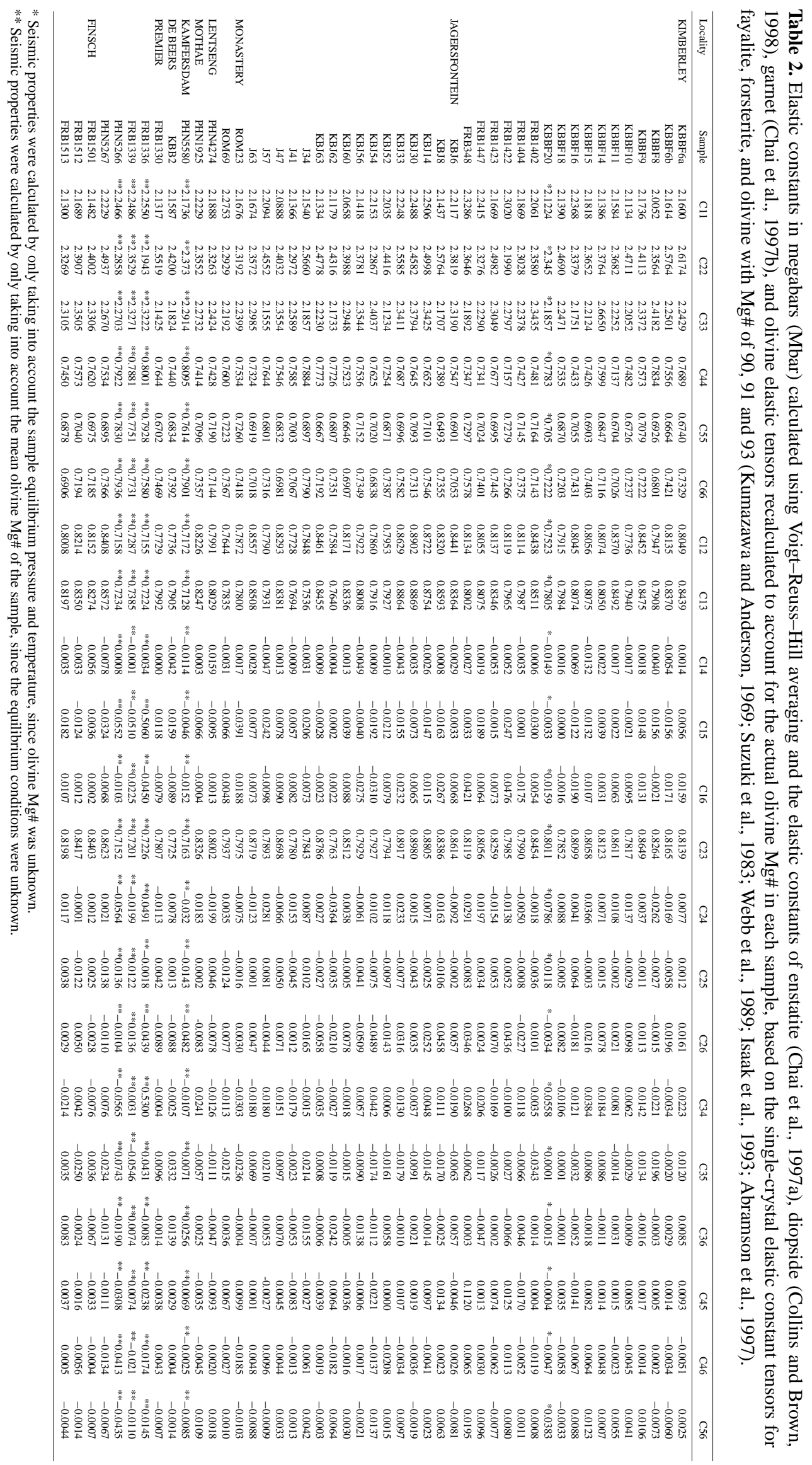



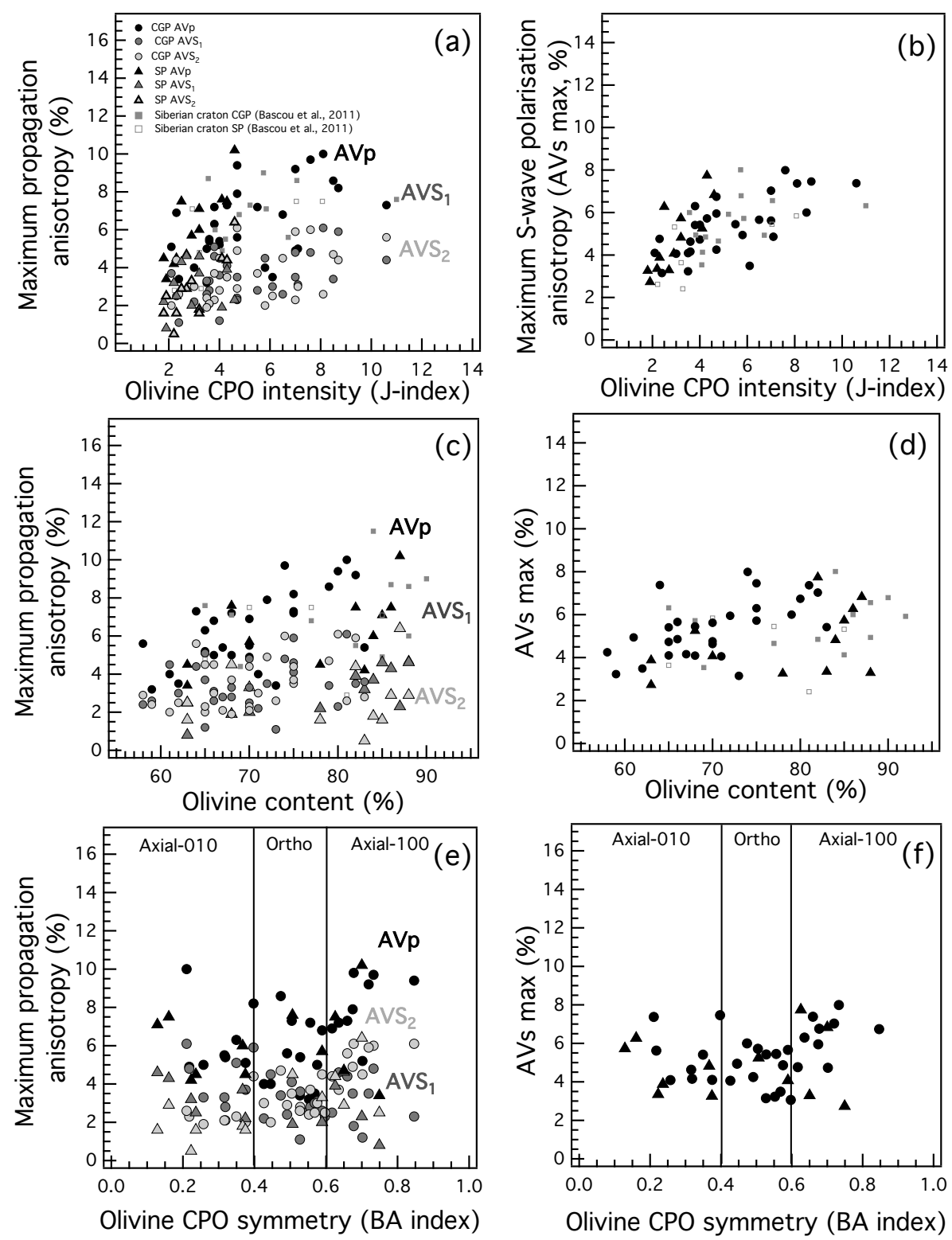

Fig. 3. Dependence of the maximum $P, S_{1}$ and $S_{2}$ wave anisotropies $\left(\mathrm{AV}_{p}, \mathrm{AV}_{1}\right.$ and $\left.\mathrm{AV}_{S_{2}}\right)$, and of the maximum $S$ wave polarization anisotropy $\left(\mathrm{AV}_{S}\right)$ on the olivine CPO strength (characterized by the $J$ index), the olivine content and the BA index.

velocities in coarse-grained peridotites also tend to increase with increasing olivine Mg\# (Fig. 4b) and decreasing orthopyroxene content (Fig. 4f), but the competing effects of olivine $\mathrm{Mg \#}$ and orthopyroxene content results in dispersion of $P$ wave velocities of the coarse-grained peridotites in all diagrams. In contrast, $P$ wave velocities in sheared peridotites increase strongly with olivine $\mathrm{Mg \#}$, probably because the latter have lower orthopyroxene contents.

The isotropic $S$ wave velocities of the Kaapvaal mantle xenoliths show a clear linear correlation with olivine $\mathrm{Mg} \#$ (Fig. 4c), varying by up to $2.4 \%$. This variation is consistent with previous data showing that an increase in the olivine
$\mathrm{Mg \#}$ in a dunite results in a linear increase in $V_{s}$ (Tommasi et al., 2004). No clear co-variation is observed between the orthopyroxene and garnet contents and $V_{S}$ in neither coarsegrained nor sheared peridotites, although $S$ wave velocities are on average higher in the coarse-grained peridotites, which have higher orthopyroxene contents (Fig. 4g and k).

The $V_{p} / V_{s}$ ratio is also sensitive to compositional changes (Fig. $4 \mathrm{~d}, \mathrm{~h}, \mathrm{l}$ ), varying by up to $2.3 \%$. It decreases with increasing olivine $\mathrm{Mg} \#$ and orthopyroxene content and increases with garnet content. The $V_{p} / V_{s}$ ratio is very sensitive to the orthopyroxene content, as indicated by the strong linear correlation between the two parameters (Fig. 4h). 

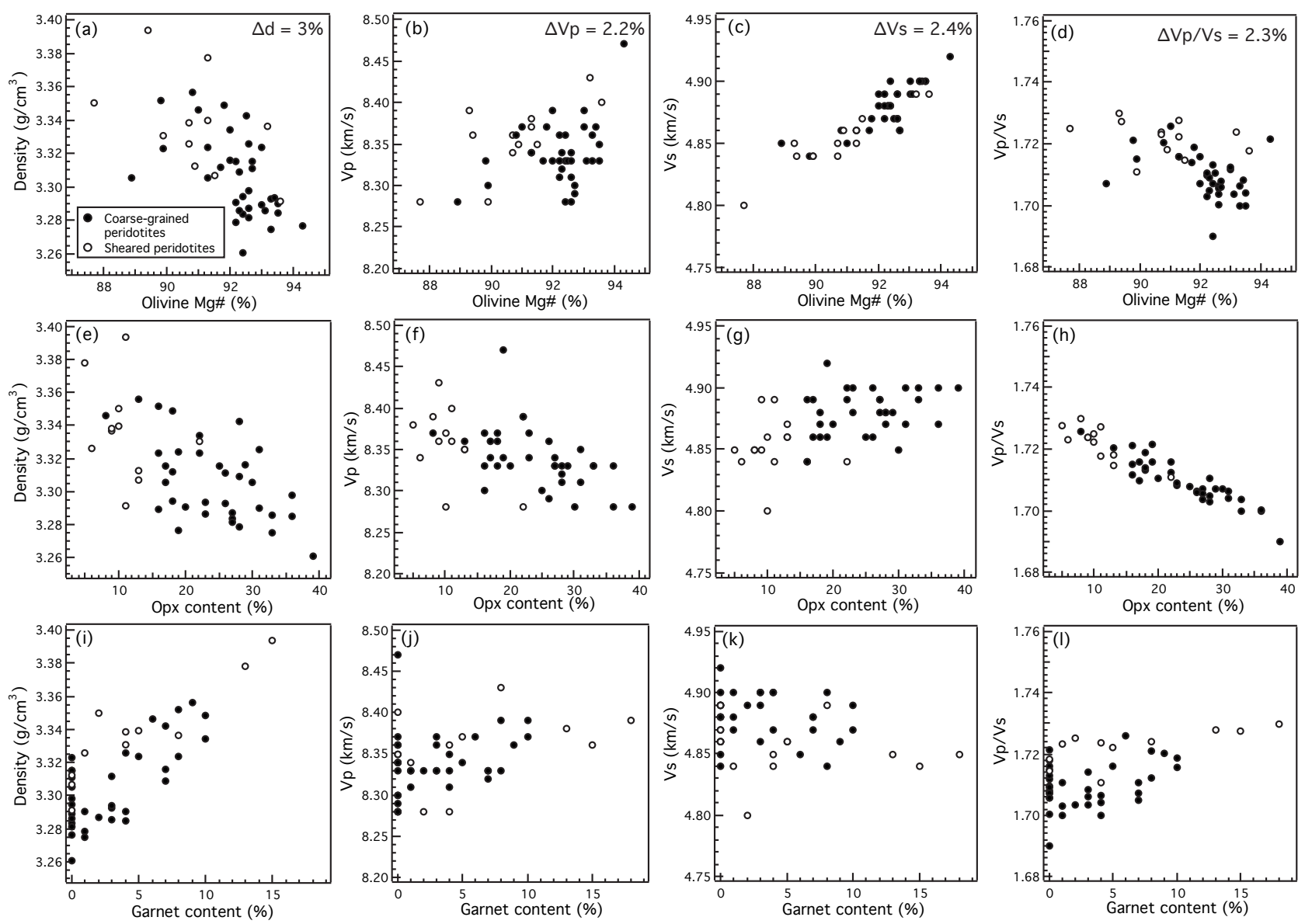

Fig. 4. Evolution of the samples' densities, $P$ wave velocities $\left(V_{p}\right), S$ wave velocities $\left(V_{S}\right)$, and $V_{p} / V_{S}$ ratios with olivine Mg\#, orthopyroxene (opx) content, and garnet contents.

Sheared peridotites have a higher and less variable $V_{p} / V_{s}$ ratio than coarse-grained peridotites, probably due to their lower modal orthopyroxene.

\subsection{Evolution of seismic properties and density with depth}

The variations of the isotropic $P$ and $S$ wave velocities $\left(V_{p}, V_{s}\right), V_{p} / V_{s}$ ratio, and density with depth in the present Kaapvaal xenolith suite and in the one studied by James et al. (2004) are plotted in Fig. 5. The isotropic $P$ wave velocities calculated for the equilibration pressure and temperature and for the composition of our samples do not show a monotonic increase with depth. They are highly heterogeneous, being comprised between 8.17 and $8.36 \mathrm{~km} \mathrm{~s}^{-1}$ over the entire depth section. This result contrasts with the one from James et al. (2004), who observed a regular increase in $V_{p}$ up to $180 \mathrm{~km}$ depth, though with some dispersion in the depth interval of $120-150 \mathrm{~km}$, and a marked decrease below this depth. One may argue that the present data set does not sample well the deepest part of the root (below $180 \mathrm{~km}$ ), but at shallower depths the peridotites analyzed in this study tend to display, on average, higher and more variable $P$ wave velocities than those reported by James et al. (2004). In contrast, the isotropic $S$ wave velocities decrease and the $V_{p} / V_{s}$ ratio increases almost linearly with depth, in excellent agreement with the results of James et al. (2004) for depths above $180 \mathrm{~km}$. The dispersion of calculated densities and $P$ wave velocities at a given depth tends to be higher than for $V_{S}$ or the $V_{p} / V_{s}$ ratio, indicating a stronger dependence on the composition.

Compositions, olivine CPOs, and anisotropic seismic properties of average samples (obtained by summing the $\mathrm{CPO}$ and averaging the compositions of all samples in a $20 \mathrm{~km}$-thick depth interval) for six depths between 70 and $190 \mathrm{~km}$ depth are presented in Fig. 6. With increasing depth, olivine and garnet contents increase, while the orthopyroxene content decreases. The variability of olivine Mg\# increases as well, with a higher proportion of normal to $\mathrm{Fe}$ rich olivines $(\mathrm{Mg} \# \leq 90)$ in the deeper part of the cratonic root, and the olivine CPO patterns change from axial [100] to more orthorhombic. These variations do not result, however, in marked changes in seismic anisotropy with depth. 

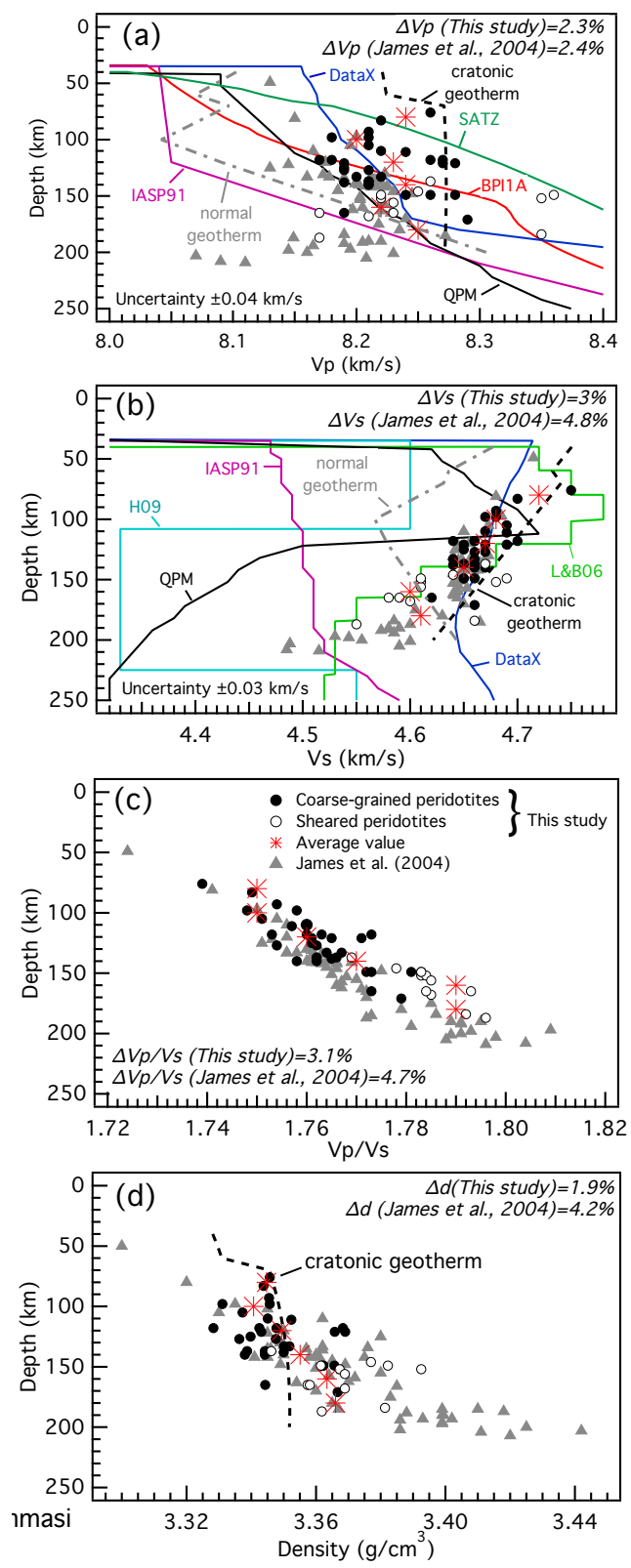

Fig. 5. Variation with depth of the isotropic seismic velocities and density of the studied peridotite xenoliths: (a) $V_{p}$, (b) $V_{s}$, (c) $V_{p} / V_{s}$ ratio, and (d) density. For comparison, the density and seismic properties of a peridotite with a standard composition (between 40 and $70 \mathrm{~km}$ : $65 \%$ olivine with Mg\#90, $23 \%$ orthopyroxene, $12 \%$ clinopyroxene; between 70 and $200 \mathrm{~km}$ : $65 \%$ olivine with $\mathrm{Mg} \# 90$, $20 \%$ orthopyroxene, $10 \%$ clinopyroxene, $5 \%$ garnet) for both a "cratonic geotherm" as estimated by Baptiste et al. (2012) and a "normal geotherm" producing a $100 \mathrm{~km}$-thick lithosphere are shown as black and gray dashed lines, respectively. The IASP91 reference model and different seismic models for southern Africa (BPI1A: Simon et al., 2002; DataX: Larson et al., 2006; H06: Hansen et al., 2009; L\&B06: Li and Burke, 2006; QPM: Qiu et al., 1996; SATZ: Zhao et al., 1999) are also shown (colored lines). Uncertainties in the seismic velocity estimates due to the uncertainty in the determination of the equilibration pressure and temperature of the xenoliths are shown in (a) and (b).
The maximum $P$ wave anisotropy varies between 4.5 and $7.9 \%$. The fastest $P$ wave propagation direction is always aligned with the olivine [100] axes maximum, that is, with the lineation. Between 70 and $110 \mathrm{~km}, P$ wave propagation is slow in all directions at high angle to the olivine [100] axes maximum. At greater depths, $P$ wave propagation is the slowest parallel to the olivine [010] axes maximum.

The maximum $S$ wave birefringence varies between 3.8 and $5.8 \%$. The fast split shear wave $\left(S_{1}\right)$ is always polarized in a plane containing the propagation direction and the olivine [100] axes maximum. The maximum $S$ wave polarization anisotropy is observed for waves propagating along the structural direction $Y$ at all depths. The apparent isotropy direction, however, changes slightly with depth. It is always contained in the $X Z$ plane (that is the plane that contains the lineation and the normal to the foliation), but it is very close to the lineation above $100 \mathrm{~km}$ depth, where axial [100] olivine $\mathrm{CPO}$ patterns dominate, and at $45^{\circ}$ to the lineation in the deeper layers, where the olivine $\mathrm{CPO}$ has a dominantly pattern.

The propagation of $S_{1}$ waves is always fastest along the foliation plane and slowest at a high angle to it, close to the $Z$ structural axis. However, the fastest propagation direction varies with depth. Between 70 and $90 \mathrm{~km}$, it is parallel to the lineation and $Y$ structural axis, while between 90 and $130 \mathrm{~km}$, it is located at $45^{\circ}$ to the lineation. At greater depths, $S_{1}$ wave propagation is fast in all directions within the foliation plane. In contrast, the $S_{2}$ wave propagation anisotropy does not change with depth. The fastest propagation direction of $S_{2}$ waves is always located on the $X Z$ plane, at about $30^{\circ}$ to the lineation, while the slowest velocities are found along the $Y Z$ plane. Finally, the $V_{p} / V_{S_{1}}$ ratio is always maximum parallel to the alignment of olivine [100] axes and minimum along the $Y Z$ plane.

\section{Discussion}

\subsection{Compositional effects on isotropic seismic properties}

In the studied data set, $P$ and $S$ wave velocities, the $V_{p} / V_{s}$ ratio, and density vary with sample composition (Fig. 4) by $2.2,2.4,2.3$, and $3 \%$, respectively. Melt depletion tends to decrease the density and the $V_{p} / V_{s}$ ratio, but to increase $V_{p}$ and $V_{s}$. Metasomatism may result in refertilization, that is, enrichment in pyroxenes and/or garnet, depending on the melt composition and depth. Enrichment in orthopyroxene decreases the whole rock density and $P$ wave velocities, but increases $S$ wave velocities and, hence, strongly reduces the $V_{p} / V_{s}$ ratio. Garnet enrichment tends to strongly increase density and slightly $P$ wave velocities and the $V_{p} / V_{s}$ ratio. However, it has little effect on $S$ wave velocities.

The $V_{p} / V_{s}$ ratio is more sensitive to orthopyroxene content than to the olivine Mg\# or garnet content. High $V_{s}$ 


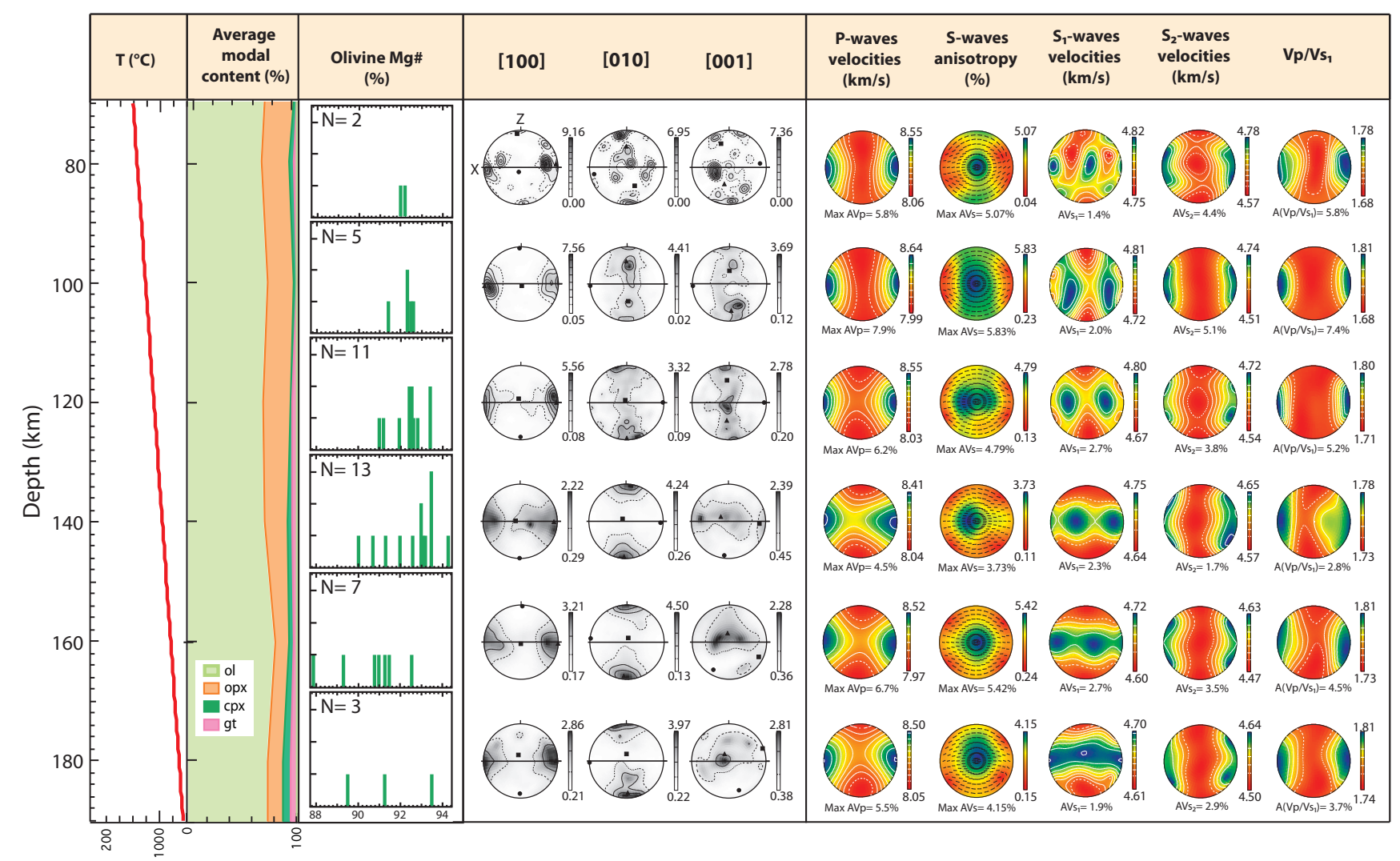

Fig. 6. Mean compositions, CPOs and seismic properties of five $20-\mathrm{km}$ sections between 70 and $190 \mathrm{~km}$ depth calculated by averaging the olivine composition and modal contents of the samples originated from these depths. From left to right, are displayed: the geotherm of Baptiste et al. (2012), the average modal content of the samples, the number and the olivine $\mathrm{Mg \#}$ of the samples in each depth section, the average olivine crystal-preferred orientations, and the 3-D distributions of $P$ wave velocities $\left(V_{p}\right), S$ wave polarization anisotropy ( $\left.V_{S}\right)$, the orientation of the fast shear wave polarization plane, $S_{1}$ wave velocities $\left(V_{S_{1}}\right), S_{2}$ wave velocities $\left(V_{S_{2}}\right)$, and $V_{p} / V_{S_{1}}$ ratio.

$\left(\sim 4.7 \mathrm{~km} \mathrm{~s}^{-1}\right)$ and low $V_{p} / V_{s}$ ratios $(1.65-1.70)$ observed locally above the flat slab in central Chile-Argentina were indeed interpreted by Wagner et al. (2008) as due to orthopyroxene enrichment. Yet, although extremely high orthopyroxene contents (> 30\%) are observed in the Kaapvaal mantle xenoliths, such an orthopyroxene enrichment can at most produce $V_{p} / V_{s}$ ratios of 1.7 . These results are consistent with $V_{p} / V_{s}$ ratios in mantle xenoliths from subduction environments, in which reactive percolation of Si-rich fluids produced enrichment of orthopyroxene at the expenses of olivine in the supra-slab mantle (Soustelle and Tommasi, 2010). This led Soustelle and Tommasi (2010) to propose that the very low $V_{p} / V_{s}$ ratios (1.65-1.70) observed locally in the mantle wedge do not result from $\mathrm{Si}$ enrichment in the mantle, but from the intrinsic anisotropy of the peridotites, representing regions in the mantle dominantly sampled by seismic waves propagating at a high angle to lineation. Analysis of the anisotropy of the $V_{p} / V_{s 1}$ ratio in the Kaapvaal peridotites (Figs. 2, 6) corroborates this conclusion.

Among the studied Kaapvaal peridotites, compositional changes result in density variations by up to $3 \%$, while $V_{p}$,
$V_{s}$ and the $V_{p} / V_{s}$ ratio vary at most by $2.4 \%$ (Fig. 4). These variation ranges are slightly higher than the $\sim 2 \%$ density and the $1.0-1.4 \% V_{s}$ changes that Griffin et al. (2009) estimated to result from an increase of fertility in the mantle lithosphere by comparing data from domains where the crust has been stable since $\geq 2.5 \mathrm{Ga}$ (Archons) and domains formed or modified at $<1 \mathrm{Ga}$ (Tectons). They are, however, in agreement with the 2-3\% seismic velocity change due compositional variations estimated by Schutt and Lesher (2010) for the Kaapvaal mantle.

The $P$ wave velocities calculated for the equilibration pressure and temperature of Kaapvaal xenoliths vary strongly at all depths (Fig. 5a). Between 90 and $150 \mathrm{~km}$, the total variation of $P$ wave velocity is of $\sim 1.2 \%$, but reaches up to $2.3 \%$ when the sheared peridotites, which were equilibrated at greater depths, are considered. Such lateral heterogeneity in $P$ wave velocity may be explained by the compositional heterogeneity of the cratonic root, as discussed above. This interpretation is corroborated by the strong variability of density at all depths (Fig. 5d). A lower proportion of deep sheared peridotites and a stronger compositional 
heterogeneity within the presently studied xenolith suite may thus explain the discrepancy between our $P$ wave data and that of James et al. (2004) (Fig. 5a). The $3 \%$ decrease in $S$ wave velocity, $3 \%$ increase in the $V_{p} / V_{s}$ ratio, and $2 \%$ increase in density with depth observed in the present study (Fig. 5b, c, d), are in good agreement with the results of James et al. (2004). These variations are the result of the conjugate effects of changes in pressure, temperature, and composition within the cratonic mantle, and corroborate a higher sensitivity of $S$ wave velocity to temperature.

To discriminate between thermal and compositional effects on $P$ and $S$ wave velocity profiles, we calculated the seismic properties and density of a sample with a standard composition (between 40 and $70 \mathrm{~km}$ : $65 \%$ olivine with Mg\#90, $23 \%$ orthopyroxene, $12 \%$ clinopyroxene; between 70 and $200 \mathrm{~km}$ : $65 \%$ olivine with Mg\#90, $20 \%$ orthopyroxene, $10 \%$ clinopyroxene, $5 \%$ garnet), for both the cratonic geotherm estimated by Baptiste et al. (2012) and a "normal" $100 \mathrm{~km}$-thick lithosphere (Fig. 5). The cooler cratonic geotherm results in an increase in $V_{p}$ and $V_{s}$ by up to 2.8 and $3.1 \%$, respectively, relative to the seismic velocities in a "normal" $100 \mathrm{~km}$-thick lithosphere. This variation is smaller than the one resulting from compositional heterogeneity among the Kaapvaal xenoliths (Fig. 5). In a 100 kmthick lithosphere, the faster increase in temperature relative to pressure results in decrease of both $P$ and $S$ wave velocities with depth; this trend is changed at sublithospheric depths, where the pressure effect becomes dominant, leading to an increase in seismic velocities. Within the cratonic mantle lithosphere, the slower temperature increase with depth is largely compensated by the increase in pressure, leading to almost constant $P$ wave velocities and a slower decrease of $S$ wave velocity with depth. The introduction of garnet at $70 \mathrm{~km}$ depth results in a sharp increase in both $P$ wave and $S$ wave velocities for both geotherms. The stronger increase in $P$ wave velocities indicates a stronger effect of this change in mineralogical composition (crystallization of garnet at the expenses of the pyroxenes and spinel) on the $P$ wave velocities relative to $S$ waves. This effect is not sampled in the present data set due to the small fraction of spinel peridotites analyzed and to the refractory composition of most shallow peridotites, which did not allow crystallization of garnet (Fig. 1, Table 1).

The marked variations in density and $S$ wave velocity among the deepest xenoliths (Fig. 5), which are mainly sheared peridotites, further highlight the strong compositional control on the isotropic seismic velocities. They may be attributed to the strong variability in the garnet content and in the olivine $\mathrm{Mg} \#$ that characterize the sheared peridotites (Fig. 4), and that has been attributed to heterogeneous refertilization shortly preceding mylonitization and extraction by the kimberlite (Smith and Boyd, 1987; Baptiste et al., 2012). At shallower depths, the variations in density can be attributed to the variability in orthopyroxene content and olivine $\mathrm{Mg \#}$.

\subsection{Comparison with seismological velocity profiles and tomographic models for the Kaapvaal mantle}

Comparison of the velocity profiles in Fig. 5 with onedimensional $P$ wave velocity $\left(V_{p}\right)$ profiles for the Kaapvaal highlights that most $P$ wave models show an increase of velocity with depth between 50 and $200 \mathrm{~km}$ depth, consistent with James et al. (2004) data (Fig. 5a). P wave velocities for our individual samples do not show a clear trend, due to the strong variability at all depths. However, except for the shallowest layer, which displays an average $V_{p}$ significantly higher than those estimated in most tomographic models, but that is only based on two samples, the average $V_{p}$ tends to increase slightly with depth. Between 90 and $180 \mathrm{~km}$, the range of variation of $V_{p}$ in the studied xenoliths is consistent with most $P$ wave tomography models, except for the SATZ model of Zhao et al. (1999), which overestimates $V_{p}$, and the global model IASP91, which as expected strongly underestimates $V_{p}$ in a cratonic root such as the Kaapvaal. The DataX model by Larson et al. (2006) is the model that fits the best our data, while the QPM model by Qiu et al. (1996) is the most coherent with the xenolith data of James et al. (2004). The decrease of $V_{p}$ associated with the predominance of deep sheared peridotites between 180 and $200 \mathrm{~km}$ in the James et al. (2004) data is not fitted by any $P$ wave tomographic model. This observation reinforces the idea that these sheared peridotites correspond to local modifications of the mantle lithosphere caused and oversampled by kimberlites.

The discrepancy between 1-D seismic profiles and xenoliths' velocities is still more marked for $S$ waves (Fig. 5b). Most models do not fit neither our, nor the xenolith-based isotropic $S$ wave velocity profiles of James et al. (2004), but there is a fit with the DataX model of Larson et al. (2006) and, in to lesser extent, with the model L\&B06 of Li and Burke (2006). The QPM model of Qiu et al. (1996) and the model of Hansen et al. (2009) (H09) display a marked decrease of $V_{s}$ at $110-120 \mathrm{~km}$ that is not observed in the xenolith data. The latter implies that the cratonic root is at least $180 \mathrm{~km}$ thick. The gradual increase in the isotropic $S$ wave velocities calculated based on Kaapvaal xenolith data (Fig. 5b) is also at odds with the seismic discontinuity imaged by $S$ wave receiver functions at $\sim 150 \mathrm{~km}$ depth (Wittlinger and Farra, 2007; Savage and Silver, 2008; Hansen et al., 2009). This suggests that this discontinuity has not a compositional origin.

$P$ and $S$ wave tomography studies reported lateral velocity perturbations of $0.5 \%$ (James et al., 2001; Fouch et al., 2004a), while surface wave studies imaged velocity perturbations as high as $5-7 \%$ within the Kaapvaal cratonic root (Ritsema and van Heijst, 2000; Priestley et al., 2006; Chevrot and Zhao, 2007; Fishwick, 2010). Priestley and Tilmann (2009) attributed the velocity variations within the Kaapvaal lithospheric mantle to thermal effects. On the contrary, Begg et al. (2009) highlighted that xenolith thermometry implies 
a very narrow geotherm range and suggested that lateral $S$ wave velocity variations within the cratonic root are mainly due to compositional changes. A characteristic example of this intracratonic seismic velocity heterogeneity are the lower velocities $\left(\sim 0.5 \%\right.$ for $V_{p}$ and $\sim 0.8 \%$ for $\left.V_{s}\right)$ imaged below the Bushveld complex by body wave tomographies (James et al., 2001; Fouch et al., 2004a) (Fig. 1), but not by surface wave tomographies (e.g., Priestley and Tilmann, 2009), probably due to their poorer lateral resolution. The degree of variation of isotropic $P$ and $S$ wave velocities observed in the present study is higher, in particular for $P$ waves, than any intracratonic velocity perturbation imaged by body wave tomographies. The latter may therefore be explained by compositional variations within the cratonic mantle lithosphere, such as, enrichment in $\mathrm{Fe}$ due to reactive melt percolation beneath the Bushveld.

The present data cannot, however, explain the much higher velocity anomalies inferred from surface wave data (7-8\%). Moreover, the variations in the xenolith $P$ wave velocity at all depths are stronger than the $S$ wave ones, what renders the explanation of the strong velocity gradients inferred from surface waves still more difficult. Partial melting within the lithosphere is a highly improbable cause for these velocity perturbations because of the cold geotherm beneath the Kaapvaal craton. The possible role of water content changes on seismic wave velocity is more difficult to access. Jacobsen et al. (2008) demonstrated that the combined effects of $3 \mathrm{~mol} \% \mathrm{Fe}$ and $0.8 \mathrm{wt} . \% \mathrm{H}_{2} \mathrm{O}$ reduce the olivine shear and bulk moduli. However, the effects of low water contents, similar to those measured in the Kaapvaal peridotites ( $\leq 150$ wt. ppm $\mathrm{H}_{2} \mathrm{O}$, Baptiste et al., 2012; Peslier et al., 2010) on olivine elastic properties are poorly constrained.

At a given depth, the calculated variation in seismic velocity is almost as strong within xenoliths derived from a single pipe or from closely spaced localities as within the entire data set. Indeed, $V_{p}$ and $V_{s}$ varies by up to $1.1 \%$ among xenoliths from Kimberley equilibrated between a 110 and $130 \mathrm{~km}$ depth (Fig. 5). $V_{p}$ and $V_{s}$ variations by up to $2.1 \%$ are observed among Jagersfontein xenoliths equilibrated between a 150 and $170 \mathrm{~km}$ depth. $V_{p}$ and $V_{s}$ variations among xenoliths from closely spaced pipes (Jagersfontein, Kimberley and DeBeers, which are all within $100 \mathrm{~km}$, Fig. 1) may reach 1.2 and $1.3 \%$ between a 110 and $130 \mathrm{~km}$ depth. Such small-scale variations cannot be imaged by seismic tomography, which probably underestimates the heterogeneity of the subcratonic lithospheric mantle.

\subsection{Seismic anisotropy}

The changes in olivine CPO symmetry of the Kaapvaal peridotite xenoliths result in slight variations of the seismic anisotropy patterns (Fig. 2). Analysis of the individual sample's seismic anisotropy shows strong variations at all depths (Table 1), but average values for different depth ranges are rather homogeneous (Fig. 6). Maximum $P$ and $S$ wave av- erage anisotropies (Fig. 6) are coherent with the values for the Kaapvaal mantle xenoliths reported by Long and Christensen (2000), but higher than those calculated by Ben Ismail et al. (2001). They are also coherent with the anisotropies calculated from Siberian xenoliths reported by Bascou et al. (2011).

The polarization and propagation anisotropies calculated for the Kaapvaal xenoliths may be compared to seismic anisotropy data obtained using both body and surface waves, which sample the Kaapvaal mantle root in different directions and with variable vertical and lateral resolutions. SKS splitting measurements sample the mantle along a vertical direction, and have no vertical but good lateral resolution ( $\sim 50 \mathrm{~km}$ at lithospheric depths), whereas surface waves sample the mantle along horizontal directions. Moreover, the analysis of surface wave data with different periods allows discriminating between the lithospheric and sublithospheric contributions to seismic anisotropy.

The fast SKS polarization, which samples vertically the Kaapvaal's lithospheric and sublithospheric mantle, and the fast Rayleigh propagation at 70-120 s periods, which sample the Kaapvaal lower lithosphere, are characterized by a NNESSW orientation within the western and central part of the craton, and an E-W orientation in its northern part (Silver et al., 2001; Adam and Lebedev, 2012). This suggests that the deep mantle lithosphere beneath the Kaapvaal displays olivine CPO with consistent orientations at the length scales of tens to hundreds of kilometers.

We can therefore use the availability of both SKS splitting and surface wave anisotropy data in the Kaapvaal craton to try to determine the orientation of the foliation and of the lineation in the lithospheric mantle beneath the Kaapvaal craton. The idea is that both SKS and surface waves sample the same mantle lithosphere, which has a unique 3-D seismic anisotropy pattern, but SKS only probes the $S$ wave polarization anisotropy in the vertical direction, while Rayleigh and Love waves travel along horizontal paths, allowing therefore to probe the $S$ wave polarization and azimuthal anisotropies in the horizontal plane. To do so, we have estimated the anisotropy that would be measured by SKS, Rayleigh $\left(S_{\mathrm{V}}\right)$ and Love $\left(S_{\mathrm{H}}\right)$ waves for five endmember orientations of the foliation and lineation (Fig. 7). A delicate point in this analysis is to determine whether the horizontally $S_{\mathrm{H}}$ or the vertically polarized $S$ wave $S_{\mathrm{V}}$ is the fast propagating $S_{1}$ wave, but this distinction can be made by analyzing the $S$ wave polarization anisotropy in the horizontal plane for each case. $S_{1}$ is always polarized in a plane containing the lineation. Hence, when the lineation is vertical, $S_{1}$ corresponds to $S_{\mathrm{V}}$ (case 3). When it is horizontal, $S_{1}$ corresponds to $S_{\mathrm{H}}$ (cases 1, 2 and 5). For a $45^{\circ}$ dipping lineation (case 4), the fastest wave is polarized in the horizontal or in the vertical plane depending on the propagation azimuth, but the birefringence is always higher when the fastest wave is polarized in the horizontal plane, implying that when significant anisotropy can be measured $S_{1}$ is equal to $S_{\mathrm{H}}$. 

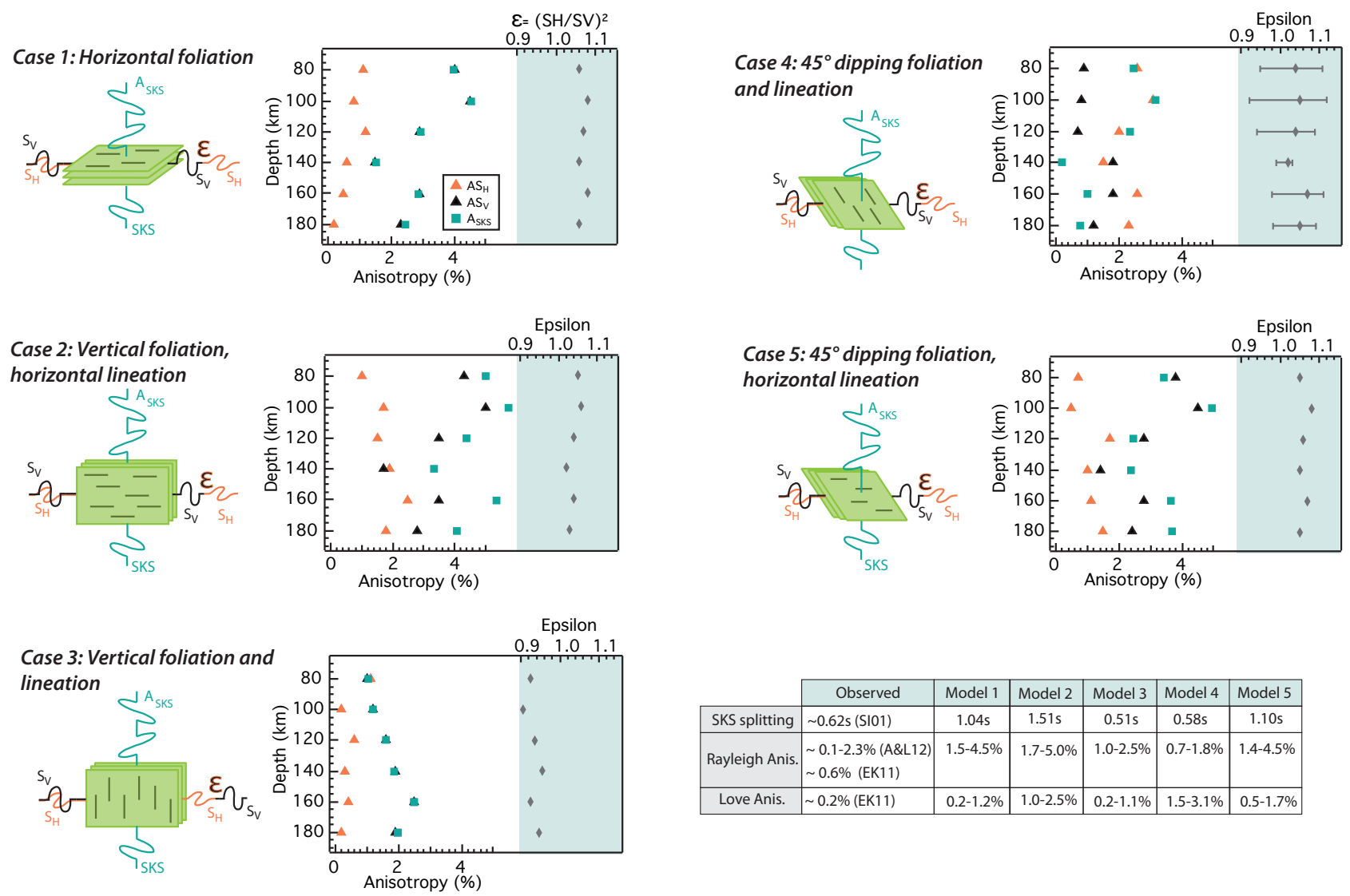

\begin{tabular}{|c|l|c|c|c|c|c|}
\cline { 2 - 7 } \multicolumn{1}{c|}{} & \multicolumn{1}{|c|}{ Observed } & Model 1 & Model 2 & Model 3 & Model 4 & Model 5 \\
\hline SKS splitting & $\sim 0.62 \mathrm{~s}$ (SI01) & $1.04 \mathrm{~s}$ & $1.51 \mathrm{~s}$ & $0.51 \mathrm{~s}$ & $0.58 \mathrm{~s}$ & $1.10 \mathrm{~s}$ \\
\hline Rayleigh Anis. & $\begin{array}{l}\text { 0.1-2.3\% (A\&L12) } \\
0.6 \% \text { (EK11) }\end{array}$ & $1.5-4.5 \%$ & $1.7-5.0 \%$ & $1.0-2.5 \%$ & $0.7-1.8 \%$ & $1.4-4.5 \%$ \\
\hline Love Anis. & $\sim 0.2 \%$ (EK11) & $0.2-1.2 \%$ & $1.0-2.5 \%$ & $0.2-1.1 \%$ & $1.5-3.1 \%$ & $0.5-1.7 \%$ \\
\hline
\end{tabular}

Fig. 7. Calculated surface wave polarization anisotropy $\left(\varepsilon=\left(S_{\mathrm{H}} / S_{\mathrm{V}}\right)^{2}\right)$, maximum azimuthal anisotropy of horizontally propagating $S_{\mathrm{H}}$ and $S_{\mathrm{V}}$, and the maximum SKS anisotropy for the depth-averaged samples in five different "endmember" orientations of the foliation and the lineation: (1) horizontal foliation, (2) vertical foliation with a horizontal lineation, (3) vertical foliation and lineation, (4) $45^{\circ}$ dipping foliation and lineation, and (5) $45^{\circ}$ dipping foliation with a horizontal lineation. The table describes how well these different "endmember" models match SKS- and surface wave data (SI01: Silver et al., 2001; A\&L12: Adam and Lebedev, 2012; EK11: Ekström, 2011).

If the foliation is horizontal (case 1), SKS waves and $\mathrm{S}_{V}$ waves will measure similar polarization and azimuthal anisotropies comprised between 1.5 and $4.5 \%$ in the mantle lithosphere, while $S_{\mathrm{H}}$ waves will detect almost no azimuthal anisotropy $(\leq 1 \%)$ at all depths. Because $S_{\mathrm{H}}$ is faster than $S_{\mathrm{V}}$, the surface wave polarization anisotropy (epsilon) is higher than 1 at all depths. If the foliation is vertical and the lineation horizontal (case 2), SKS waves sample a highly anisotropic direction (3.5 to $5.5 \%$ ) at all depths. The $S_{\mathrm{V}}$ wave propagation $(2-4 \%)$ anisotropy is, at all depths, twice as strong as that of the $S_{\mathrm{H}}$ waves $(1-2 \%)$. As in case 1 , the surface wave polarization anisotropy is higher than 1 at all depths. If the foliation and the lineation are vertical (case 3 ), the surface wave polarization anisotropy is smaller than 1 , indicating that $S_{\mathrm{V}}$ is always faster than $S_{\mathrm{H}}$. SKS and $S_{\mathrm{V}}$ waves will measure low anisotropies, comprised between 1.0 and $2.5 \%$. The anisotropy measured by $S_{\mathrm{H}}$ waves should be even lower $(<0.5 \%)$. A $45^{\circ}$ dipping foliation and lineation (case 4) should produce SKS anisotropies higher than $2 \%$ and $S_{\mathrm{V}}$ wave azimuthal anisotropy lower than $1 \%$ between
80 and $120 \mathrm{~km}$. At greater depths, SKS wave anisotropy will be lower than $1 \%$, while $S_{\mathrm{V}}$ wave azimuthal anisotropy will vary between 1 and $2 \%$. The $S_{\mathrm{H}}$ wave azimuthal anisotropy will always be comprised between 1.5 and $2 \%$. The surface wave polarization anisotropy will be strongly dependent on the propagation direction. Finally, if we consider a $45^{\circ}$ dipping foliation and a horizontal lineation (Case 5), the SKS and $S_{\mathrm{V}}$ waves should measure polarization and azimuthal anisotropies varying between 1.5 and $5 \%$, while $S_{\mathrm{H}}$ waves will measure azimuthal anisotropies lower than $2 \%$. As in cases 1 and 2, the surface wave polarization anisotropy is higher than 1, indicating that $S_{\mathrm{H}}$ is faster than $S_{\mathrm{V}}$ at all depths.

These predictions can be compared to the anisotropy detected using SKS and surface waves (Table in Fig. 7). Beneath the Kaapvaal craton, SKS delay times are low. Vinnik et al. (1995) first measured SKS delay times comprised between 0.4 and $1.4 \mathrm{~s}$. Silver et al. (2001) obtained similar SKS delay times, between 0.3 and $1.1 \mathrm{~s}$, with an average value of $0.62 \mathrm{~s}$. Low delay times ( 0.15 to $0.75 \mathrm{~s}$ ) were also obtained in 
a denser network near Kimberley by Fouch et al. (2004b). If we consider a $150 \mathrm{~km}$-thick homogeneous anisotropic lithospheric mantle, these delay times yield anisotropies comprised between 0.9 and $3.4 \%$, with an average of $1.9 \%$. Such low SKS anisotropies are only obtained for either a vertical or a $45^{\circ}$ dipping foliation and lineation (cases 3 and 4 in Fig. 7).

Surface wave data consistently points to $S_{\mathrm{H}}$ faster than $S_{\mathrm{V}}$ in the Kaapvaal lithospheric mantle (Freybourger et al., 2001; Sergei Lebedev, personal communication). This is consistent with receiver function data, which imaged a $160 \mathrm{~km}$-thick anisotropic mantle keel with vertical slow axis $\left(V_{S_{\mathrm{H}}}>V_{S_{\mathrm{V}}}\right)$ and decreasing anisotropy with depth due to a decrease in $V_{S_{\mathrm{H}}}$ while $V_{S_{\mathrm{V}}}$ remains constant (Wittlinger and Farra, 2007). These observations are not consistent with case 3 (Fig. 7), since vertical lineations always result in $V_{S_{\mathrm{H}}}<V_{S_{\mathrm{V}}}$. Moreover, coherent fast SKS polarization directions like those measured by Silver et al. (2001) are not expected if the lineation is vertical (case 3). They might however be produced by a $45^{\circ}$ dipping foliation (case 4 ). Surface wave azimuthal anisotropies generated for case 4 range between 0.5 and $3 \%$, being consistent with the low azimuthal anisotropies inferred in both global and regional surface wave models (Ekström, 2011; Adam and Lebedev, 2012). However, case 4 produces a $S_{\mathrm{H}}$ azimuthal anisotropy that is stronger than the $S_{\mathrm{V}}$ one, which is not consistent with the stronger Rayleigh azimuthal anisotropy $(\sim 2 \%)$ relative to the Love azimuthal anisotropy ( $\sim 1 \%)$ imaged beneath South Africa in the global surface wave model of Ekström (2011), and in the recent regional anisotropic tomography model for the Kaapvaal by Adam and Lebedev (2012). Such a relation is obtained in the cases where the lineation is horizontal (cases 1, 2, and 5 in Fig. 7), but too strong Rayleigh azimuthal and SKS polarization anisotropies accompany it.

Low SKS birefringence may result from vertical variations of the seismic anisotropy. Indeed, beneath the western Kaapvaal (Kimberley block), the Rayleigh wave azimuthal anisotropy shows a change of fast propagation directions from N-S in the crust to E-W in the mantle (Adam and Lebedev, 2012). A change with depth in the orientation of the fast direction from $\mathrm{E}-\mathrm{W}$ to $\mathrm{N}-\mathrm{S}$ was also detected at depths $>160 \mathrm{~km}$ beneath the Limpopo belt by a study associating $P$ wave receiver functions and SKS waveforms inversion (Vinnik et al., 2012). The seismic discontinuity imaged by $S$ wave receiver functions at $\sim 150 \mathrm{~km}$ depth (Wittlinger and Farra, 2007; Savage and Silver, 2008; Hansen et al., 2009) also points to vertical variations in the deformation structure within the cratonic root, since drastic changes in composition or $S$ wave velocities with depth are not observed in neither our data set nor in that of James et al. (2004). Most cases presented in Fig. 7 show a decrease in anisotropy at $140 \mathrm{~km}$ depth, which would be consistent with the observations of Wittlinger and Farra (2007), but the associated gradient in seismic velocities is too weak to produce a strong impedance contrast. Peslier et al. (2010) and Baptiste et al. (2012) did measure a marked decrease in $\mathrm{OH}$ concentrations in olivine at depths greater than $160 \mathrm{~km}$. Yet the change in elastic properties produced by variations of $\mathrm{OH}$ contents from $150 \mathrm{ppm}$ to a few ppm is probably too weak (Jacobsen et al., 2008) to explain the receiver function signal. A sharp change in the orientation of the foliation and lineation and the associated change in seismic anisotropy might produce the needed impedance contrast. It is also consistent with the anisotropic surface wave models and with the results of $P$ receiver functions and SKS waveforms inversion, which propose change in the orientation of the fast direction at depths $>160 \mathrm{~km}$ (Adam and Lebedev, 2012; Vinnik et al., 2012). However, such a vertical variation in seismic anisotropy should produce a backazimuthal dependence of the shear wave splitting, which was not described in the regional studies (Silver et al., 2001; Fouch et al., 2004a; Silver et al., 2004; Vinnik et al., 1995).

In conclusion, no simple model may account for all seismic anisotropy data in the Kaapvaal. The two models that best explain the observations are (i) the presence of dipping foliations and lineations within the cratonic lithosphere, at ca. $160 \mathrm{~km}$ depth and (ii) a vertical variation in seismic anisotropy within the Kaapvaal mantle lithosphere, with dominant horizontal frozen flow directions in the shallower layer. In the second case, we may speculate that it might represent an interface marking a change in the geodynamical process responsible for the formation and thickening of the mantle root. A possible geodynamic scenario allowing for the development of $45^{\circ}$ dipping foliations and lineations within the cratonic lithosphere would be the formation of the Kaapvaal craton keel by subduction stacking, as suggested by several geochemical and petrological studies (Shirey et al., 2001; Simon et al., 2007; Pearson and Wittig, 2008). However, in this case, fast SKS polarization directions normal to the main sutures should be expected, rather than the parallel to slightly oblique directions measured in the Kaapvaal craton (Silver et al., 2001). These predictions are also at odds with the parallelism between fast Rayleigh wave propagation directions and the Archean-Paleoproterozoic crustal structures in the Limpopo belt and in the northern Kaapvaal, but they may explain the fast Rayleigh wave propagation directions perpendicular to the crustal structures in the western part of the craton (Adam and Lebedev, 2012). On the other hand, if the cratonic root formed by episodic injection of small (100-200 km) diapiric upwellings (de Smet et al., 1998, 1999), a horizontal foliation and variable flow direction are to be expected across the craton. Such a variability of the structure within the root may explain the low SKS delay times measured in the craton, but would fail to explain the coherent fast polarization direction of SKS waves and fast propagation direction of Rayleigh waves over length scales of several hundreds of kilometers in the Kaapvaal mantle lithosphere (Silver et al., 2001; Adam and Lebedev, 2012). 


\section{Conclusions}

The strong compositional heterogeneity of the Kaapvaal peridotite xenoliths results in up to $3 \%$ variation in density, while $V_{p}, V_{s}$ and the $V_{p} / V_{s}$ ratio vary by up to $2.3 \%$. These variations are slightly higher than the velocity perturbations imaged by body wave tomography, but cannot explain the strong velocity anomalies reported by surface wave studies. Melt depletion tends to increase $V_{p}$ and $V_{s}$ and to decrease the $V_{p} / V_{s}$ ratio and density. Orthopyroxene enrichment decreases the density and $V_{p}$, and strongly reduces the $V_{p} / V_{s}$ ratio. Enrichment in garnet tends to increase the density strongly and slightly $V_{p}$ and the $V_{p} / V_{s}$ ratio, but has little to no effect on $V_{s}$. The $V_{p} / V_{s}$ ratio is more sensitive to the orthopyroxene content than to olivine $\mathrm{Mg} \#$ and garnet content. The present data also highlights that compositional heterogeneity in the Kaapvaal mantle root occurs at a scale much smaller than the one that may be sampled by seismic tomography, since at a given depth, the calculated variation in seismic velocity within xenoliths derived from a single pipe or from closely spaced localities is almost as strong as within the entire data set. Seismic tomography thus probably strongly underestimates the heterogeneity of the subcratonic lithospheric mantle.

Vertical density and seismic velocity profiles calculated using the xenoliths' compositions and equilibration conditions show that $V_{s}$ decreases, whereas the $V_{p} / V_{s}$ ratio and density increase with increasing depth. $V_{p}$ does not show a clear trend; it is highly variable at all depths. Comparison of these xenolith-based seismic profiles with 1-D velocity profiles derived from seismological data in the Kaapvaal highlights clear discrepancies between seismological and xenolith-based data. For $P$ waves, the DataX model by Larson et al. (2006) fits our data the best, while the QPM model by Qiu et al. (1996) is the most coherent with data of James et al. (2004). For $S$ waves, most models, except for the DataX model of Larson et al. (2006) and, in a lesser extent, the model L\&B06 of Li and Burke (2006), do not fit neither our, nor data of James et al. (2004), which imply that the cratonic root is at least $180 \mathrm{~km}$ thick. No seismological velocity model fits the decrease of $V_{p}$ indicated by deep sheared peridotites between 180 and $200 \mathrm{~km}$, reinforcing the idea that they represent very local modifications of the lithosphere caused and oversampled by kimberlites.

Changes in olivine CPO symmetry of the Kaapvaal peridotite xenoliths result only in slight variation of the seismic anisotropy patterns. Seismic anisotropy increase with the olivine $J$ index and olivine content, but there is no simple relation with the olivine CPO symmetry (BA index). Maximum anisotropy values range between 2.5 and $10.2 \%$ for $P$ wave azimuthal anisotropy $\left(\mathrm{AV}_{p}\right)$ and between 2.7 and $8 \%$ for $S$ wave polarization anisotropy $\left(\mathrm{AV}_{s}\right)$ in agreement with existing xenolith data. The maximum $P$ wave anisotropy of each $20 \mathrm{~km}$ interval varies between 4.5 and $7.9 \%$, whereas $S$ wave anisotropy is comprised between 3.7 and $5.8 \%$. Mod- els considering endmember orientations of the foliation and lineation in the subcratonic mantle lithosphere show that the simplest model that might produce both coherent fast directions over large domains, but low delay times imaged by SKS studies, and the low azimuthal surface wave anisotropy with $S_{\mathrm{H}}$ faster than $S_{\mathrm{V}}$ in the subcratonic mantle lithosphere is the presence of $45^{\circ}$ dipping foliations and lineations. Yet, this model fails to account for the relative importance of the Rayleigh and Love azimuthal anisotropies. This observation and the discontinuity observed at ca. $160 \mathrm{~km}$ depth by receiver functions are best explained by a vertical variation in seismic anisotropy, due to a sharp change in orientation of the frozen deformation structures in the Kaapvaal mantle lithosphere. However, this scenario is at odds with the observation of coherent fast polarization direction of SKS waves and fast propagation direction of Rayleigh waves over scales of several hundreds of kilometers in the Kaapvaal mantle lithosphere (Silver et al., 2001; Adam and Lebedev, 2012).

Acknowledgements. The authors thank A. Vauchez and D. Mainprice for helpful discussions. D. Mainprice provided the programs for calculating seismic properties. C. Nevado and D. Delmas are thanked for providing high-quality polishing of sections for EBSD measurements. The two anonymous reviewers are thanked for their helpful comments. The EBSD-SEM national facility in Montpellier is supported by the Institut National de Sciences de l'Univers (INSU) du Centre National de la Recherche Scientifique (CNRS), France and by the Conseil Régional Languedoc-Roussillon, France.

Edited by: W. Geissler

\section{References}

Abramson, E. H., Brown, J. M., Slutsky, L. J., and Zaug, J.: The elastic constants of San Carlos olivine to $17 \mathrm{GPa}$, J. Geophys. Res., 102, 12253-12263, 1997.

Adam, J. M.-C.and Lebedev, S.: Azimuthal anisotropy beneath southern Africa from very broad-band surface wave dispersion measurements, Geophys. J. Int., 191, 155-174, 2012.

Adams, A. and Nyblade, A.: Shear wave velocity structure of the southern African upper mantle with implications for the uplift of southern Africa, Geophys. J. Int., 186, 808-824, 2011.

Allsopp, H. L., Bristow, J. W., and Skinner, E. M. W.: The RbSr geochronology of the Colossus kimberlite pipe, Zimbabwe, Transactions of the Geological Society of South Africa, 88, 245248, 1985.

Baptiste, V., Tommasi, A., and Demouchy, S.: Deformation and hydration of the lithospheric mantle beneath the Kaapvaal craton, South Africa, Lithos, 149, 31-50, 2012.

Bascou, J., Doucet, L. S., Saumet, S., Ionov, D. A., Ashchepkov, I. V., and Golovin, A. V.: Seismic velocities, anisotropy and deformation in Siberian cratonic mantle: EBSD data on xenoliths from the Udachnaya kimberlite, Earth Planet. Sc. Lett., 304, 71-84, 2011

Begg, G. C., Griffin, W. L., Natapov, L. M., O’Reilly, S. Y., Grand, S. P., O’Neill, C. J., Hronsky, J. M. A., Poudjom Djo- 
mani, Y., Swain, C. J., Deen, T., and Bowden, P.: The lithospheric architecture of Africa: seismic tomography, mantle petrology, and tectonic evolution, Geosphere, 5, 23-50, 2009.

Bell, D. R., Rossman, G. R., Maldener, J., Endisch, D., and Rauch, F.: Hydroxide in olivine: a quantitative determination of the absolute amount and calibration of the IR spectrum, J. Geophys. Res., 108, B2, ECV8.1-ECV8.9, 2003.

Bell, D., Grégoire, M., Grove, T., Chatterjee, N., Carlson, R., and Buseck, P.: Silica and volatile-element metasomatism of Archean mantle: a xenolith-scale example from the Kaapvaal Craton, Contrib. Mineral. Petr., 150,251-267, 2005.

Ben Ismaïl, W., and Mainprice, D.: An olivine fabric database: an overview of upper mantle fabrics and seismic anisotropy, Tectonophysics, 296, 145-157, 1998.

Ben Ismail, W., Barruol, G., and Mainprice, D.: The Kaapvaal craton seismic anisotropy: petrophysical analyses of upper mantle kimberlite nodules, Geophys. Res. Lett., 28, 2497-2500, 2001.

Chai, M., Brown, J. M, and Slutsky, L. J.: The elastic constants of an aluminous orthopyroxene to $12.5 \mathrm{GPa}$, J. Geophys. Res., 102, 14770-14785, 1997a.

Chai, M., Brown, J. M., and Slutsky, L. J.: The elastic constants of pyrope-grossular-almandine garnets to $20 \mathrm{GPa}$, Geophys. Res. Lett., 24, 523-526, 1997b.

Chevrot, S. and Zhao, L.: Multiscale finite-frequency Rayleigh wave tomography of the Kaapvaal craton, Geophysical Journal International, 169, 1, 201-215, 2007.

Collins, M. D. and Brown, J. M.: Elasticity of an upper mantle clinopyroxene, Phys. Chem. Miner., 26, 7-13, 1998.

de Smet, J. H., van den Berg, A. P., and Vlaar, N. J.: Stability and growth of the continental shields in mantle convection models including melt production, Tectonophysics, 296, 15-29, 1998.

de Smet, J. H., van den Berg, A. P., and Vlaar, N. J.: The evolution of continental roots in numerical thermo-chemical mantle convection models including differentiation by partial melting, Lithos, 48, 153-170, 1999.

Ekström, G.: A global model of Love and Rayleigh surface wave dispersion and anisotropy, 25-250 s, Geophys. J. Int., 187, 16681686, 2011.

Fishwick, S.: Surface wave tomography: imaging of the lithosphereasthenosphere boundary beneath central and southern Africa?, Lithos, 120, 63-73, 2010.

Fouch, M. J., James, D. E., VanDecar, J. C., and van der Lee, S.: Mantle seismic structure beneath the Kaapvaal and Zimbabwe Cratons, S. Afr. J. Geol., 107, 33-44, 2004a.

Fouch, M. J., Silver, P. G., Bell, D. R., and Lee, J. N.: Small-scale variations in seismic anisotropy near Kimberley, South Africa, Geophys. J. Int., 157, 764-774, 2004 b.

Freybourger, M., Gaherty, J. B., Jordan, T. H., and the Kaapvaal Seismic Group: Structure of the Kaapvaal craton from surface waves, Geophys. Res. Lett., 28, 2489-2492, 2001.

Green, H. W. and Gueguen, Y.: Origin of kimberlite pipes by diapiric upwelling in upper mantle, Nature, 249, 617-620, 1974.

Grégoire, M., Bell, D. R., and Le Roex, A. P.: Garnet lherzolites from the Kaapvaal craton (South Africa): trace element evidence for a metasomatic history, J. Petrol., 44, 629-657, 2003.

Griffin, W. L., O’Reilly, S. Y., Afonso, J. C., and Begg, G. C.: The composition and evolution of lithospheric mantle: a re-evaluation and its tectonic implications, J. Petrol., 50, 7, 1185-1204, 2009.
Griffin, W. L., O’Reilly, S. Y., Natapov, L. M.,and Ryan, C. G.: The evolution of lithospheric mantle beneath the Kalahari craton and its margins, Lithos, 71, 215-241, 2003.

Hansen, S. E., Nyblade, A. A., Julià, J., Dirks, P. H. G. M., and Durrheim, R. J.: Upper-mantle low-velocity zone structure beneath the Kaapvaal craton from $S$ wave receiver functions, Geophys. J. Int., 178, 1021-1027, 2009.

Hielscher, R. and Schaeben, H.: A novel pole figure inversion method: specification of the MTEX algorithm, J. Appl. Crystallogr., 41, 1024-1037, 2008.

Isaak, D., Graham, E. K., Bass, J. D., and Wang, H.: The elastic properties of single-crystal fayalite as determined by dynamical measurement techniques, Pure Appl. Geophys., 141, 393-414, 1993.

Jacobsen, S. D., Jiang, F., Mao, Z., Duffy, T. S., Smyth, J. R., Holl, C. M., and Frost, D. J.: Effects of hydration on the elastic properties of olivine, Geophys. Res. Lett., 35, L14303, doi:10.1029/2008GL034398, 2008.

James, D. E., Fouch, M. J., Vandecar, J. C., and Van der Lee, S.: Tectospheric structure beneath southern Africa: The Kaapvaal Project: formation and evolutions of cratons, Geophys. Res. Lett., 28, 2485-2488, 2001.

James, D. E., Boyd, F. R., Schutt, D., Bell, D. R., and Carlson, R. W.: Xenolith constraints on seismic velocities in the upper mantle beneath southern Africa, Geochem. Geophy. Geosy., 5, Q01002, doi:10.1029/2003GC000551, 2004.

Jordan, T. H.: Composition and development of continental tectosphere, Nature, 274, 5671, 544-548, 1978.

Kramers, J. D.and Smith, C. B.: A feasibility study of U-Pb and $\mathrm{Pb}-\mathrm{Pb}$ dating of kimberlites using groundmass mineral fractions and whole-rock samples, Chem. Geol., 41, 23-38, 1983.

Kumazawa, M. and Anderson, O. L.: Elastic moduli, pressure derivatives, and temperature derivatives of single-crystal olivine and single-crystal forsterite, J. Geophys. Res., 74, 5961-5972, 1969.

Larson, M. A., Snoke, J. A., and James, D. E.: $S$-wave velocity structure, mantle xenoliths and the upper mantle beneath the Kaapvaal craton, Geophys. J. Int., 167, 171-186, 2006.

Li, A. and Burke, K.: Upper mantle structure of southern Africa from Rayleigh wave tomography, J. Geophys. Res., 111, B10303, doi:10.1029/2006JB004321, 2006.

Long, C. and Christensen, N. I.: Seismic anisotropy of South African upper mantle xenoliths, Earth Planet. Sc. Lett., 179, 551$565,2000$.

Mainprice, D.: A FORTRAN program to calculate seismic anisotropy from the lattice preferred orientation of minerals, Computat. Geosci., 16, 385-393, 1990.

Mainprice, D. and Humbert, M.: Methods of calculating petrophysical properties from lattice preferred orientation data, Surv. Geophys., 15, 575-592, 1994.

Mainprice, D. and Silver, P. G.: Interpretation of SKS-waves using samples from the subcontinental lithosphere, Phys. Earth Planet. In., 78, 257-280, 1993.

Mainprice, D., Barruol, G., and Ben Ismaill, W.: The seismic anisotropy of the Earth's mantle: from single crystal to polycrystal, in: AGU Geophysical Monograph, edited by: Karato, A. M. F. S., Libermann, R. C., Masters, G., and Stixrude, L., AGU, Washington, DC, 117, 237-264, 2000. 
Mainprice, D., Hielscher, R., and Schaeben, H.: Calculating anisotropic physical properties from texture data using the MTEX open source package, in: Deformation Mechanisms, Rheology and Tectonics: Microstructures, Mechanics and Anisotropy, edited by: Prior, D. J., Rutter, E. H., and Tatham, D. J., Geological Society, Special Publications, London, 175-192, 2011.

Pearson, D. G. and Wittig, N.: Formation of Archaean continental lithosphere and its diamonds: the root of the problem, J. Geol. Soc., 165, 895-914, 2008.

Pearson, D. G., Carlson, R. W., Shirey, S. B., Boyd, F. R., and Nixon, P. H.: Stabilisation of Archaean lithospheric mantle: A Re-Os isotope study of peridotite xenoliths from the Kaapvaal craton, Earth Planet. Sci. Lett., 134, 341-357, 1995.

Peslier, A. H., Woodland, A. B., Bell, D. R., and Lazarov, M.: Olivine water contents in the continental lithosphere and the longevity of cratons, Nature, 467, 78-81, 2010.

Phillips, D., Machin, K. J., Kiviets, G. B., Fourie, L. F., Roberts, M. A., Skinner, E. M. W.: A petrographic and ${ }^{40} \mathrm{Ar} /{ }^{39} \mathrm{Ar}$ geochronological study of the Voorspoed kimberlite, South Africa: implications for the origin of group II kimberlite magmatism, special issue, S. Afr. J. Geol., 101, 299-306, 1998.

Priestley, K.: Velocity structure of the continental upper mantle: evidence from southern Africa, Lithos, 48, 45-56, 1999.

Priestley, K. and Tilmann, F.: Relationship between the upper mantle high velocity seismic lid and the continental lithosphere, Lithos, 109, 112-124, 2009.

Priestley, K., McKenzie, D., and Debayle, E.: The state of the upper mantle beneath southern Africa, Tectonophysics, 416, 101-112, 2006.

Qiu, X., Priestley, K., and McKenzie, D.: Average lithospheric structure of southern Africa, Geophys. J. Int., 127, 563-587, 1996.

Ritsema, J. and van Heijst, H.: New seismic model of the upper mantle beneath Africa, Geology, 28, 63-66, 2000.

Savage, B. and Silver, P. G.: Evidence for a compositional boundary within the lithospheric mantle beneath the Kalahari craton from $S$ receiver functions, Earth Planet. Sc. Lett., 272, 600-609, 2008.

Schutt, D. L. and Lesher, C. E.: Compositional trends among Kaapvaal Craton garnet peridotite xenoliths and their effects on seismic velocity and density, Earth Planet. Sc. Lett., 300, 367-373, 2010.

Sebai, A., Stutzmann, E., Montagner, J.-P., Sicilia, D., and Beucler, E.: Anisotropic structure of the African upper mantle from Rayleigh and Love wave tomography, Phys. Earth Planet. In., 155, 48-62, 2006.

Shirey, S. B., Carlson, R. W., Richardson, S. H., Menzies, A. H., Gurney, J. J., Pearson, D. G., Harris, J. W., and Wiechert, U.: Archean emplacement of eclogitic components into the lithospheric mantle during formation of the Kaapvaal Craton, Geophys. Res. Lett., 28, 2509-2512, 2001.

Silver, P. G., Gao, S. S., Liu, K. H., and the Kaapvaal Seismic Group: Mantle deformation beneath southern Africa, Geophys. Res. Lett., 28, 2493-2496, 2001.

Silver, P. G., Fouch, M. J., Gao, S. S., Schmitz, M., and the Kaapvaal Seismic Group: Seismic anisotropy, mantle fabric, and the magmatic evolution of Precambrian southern Africa, S. Afr. J. Geol., 107, 45-58, 2004.
Simon, R. E., Wright, C., Kgaswane, E. M., and Kwadiba, M. T. O.: The $P$ wavespeed structure below and around the Kaapvaal craton to depths of $800 \mathrm{~km}$, from traveltimes and waveforms of local and regional earthquakes and mining-induced tremors, Geophys. J. Int., 151, 132-145, 2002.

Simon, N. S. C., Carlson, R. W., Pearson, D. G., and Davies, G. R.: The origin and evolution of the Kaapvaal cratonic lithospheric mantle, J. Petrol., 48, 3, 589-625, 2007.

Smith, D. and Boyd, F. R.: Compositional heterogeneities in a high temperature lherzolite nodule and implications for mantle processes, in: Mantle Xenoliths, edited by: Nixon, P. H., John Wiley, Hoboken, NJ, 551-561, 1987.

Soustelle, V. and Tommasi, A.: Seismic properties of the suprasubduction mantle: constraints from peridotite xenoliths from the Avacha volcano, southern Kamchatka, Geophys. Res. Lett., 37, L13307, 1-5, 2010.

Suzuki, I., Anderson, O. L., and Sumino, Y.: Elastic properties of a single-crystal forsterite $\mathrm{Mg}_{2} \mathrm{SiO}_{4}$, up to $1,200 \mathrm{~K}$, Phys. Chem. Miner., 10, 38-46, 1983.

Tommasi, A., Mainprice, D., Canova, G., and Chastel, Y.: Viscoplastic self-consistent and equilibrium-based modeling of olivine lattice preferred orientations: Implications for the upper mantle seismic anisotropy, J. Geophys. Res., 105, 7893-7908, 2000.

Tommasi, A., Godard, M., Coromina, G., Dautria, J.-M., and Barsczus, H.: Seismic anisotropy and compositionally induced velocity anomalies in the lithosphere above mantle plumes: a petrological and microstructural study of mantle xenoliths from French Polynesia, Earth Planet. Sc. Lett., 227, 539-556, 2004.

Tommasi, A., Vauchez, A., and Ionov, D. A.: Deformation, static recrystallisation, and reactive melt transport in shallow subcontinental mantle xenoliths (Tol Cenozoic volcanic field, SE Siberia), Earth Planet. Sc. Lett., 272,65-77, 2008.

Vinnik, L., Green, R. W. E., and Nicolaysen, L. O.: Recent deformation of the deep continental root beneath southern Africa, Nature, 375, 50-52, 1995.

Vinnik, L., Kiselev, S., Weber, M., Oreshin, S., and Makeyeva, L.: Frozen and active seismic anisotropy beneath southern Africa, Geophys. Res. Lett., 39,1-6, 2012.

Wagner, L. S., Anderson, M. L., Jackson, J. M., Beck, S. L., and Zandt, G.: Seismic evidence for orthopyroxene enrichment in the continental lithosphere, Geology, 36, 12, 935-938, 2008.

Wang, Y., Wen, L., and Weidner, D.: Upper mantle $S_{\mathrm{H}^{-}}$and $P$ velocity structures and compositional models beneath southern Africa, Earth Planet. Sc. Lett., 297, 596-608, 2008.

Wasch, L. J., van der Zwan, F. M., Nebel, O., Morel, M. L. A., Hellebrand, E. W. G., Pearson, D. G., and Davies, G. R.: An alternative model for silica enrichment in the Kaapvaal subcontinental lithospheric mantle, Geochim. Cosmochim. Ac., 73, 68946917, 2009.

Webb, S. L.: The elasticity of the upper mantle orthosilicates olivine and garnet to $3 \mathrm{GPa}$, Phys. Chem. Miner., 16, 684-692, 1989.

Wittlinger, G. and Farra, V.: Converted waves reveal a thick and layered tectosphere beneath the Kalahari super-craton, Earth Planet. Sc. Lett., 254, 404-415, 2007.

Zhao, M., Langston, C. A., Nyblade, A., and Owens, T. J.: Upper mantle velocity structure beneath southern Africa from modeling regional seismic data, J. Geophys. Res., 104, 4783-4794, 1999. 